\title{
Gaining a New Perspective on Life as a Consequence of Uncertainty in HIV Infection
}

\author{
By
}

\author{
Anne Katz
}

A Thesis

Submitted to the Faculty of Graduate Studies in Partial Fulfillment of the Requirements for the Degree of

Master of Nursing

Faculty of Nursing

University of Manitoba

Winnipeg, Manitoba

(CMay, 1995 
National Library

of Canada

Acquisitions and

Bibliographic Services Branch

395 Wellington Street

Ottawa, Ontario

K1A ON4
Bibliothèque nationale

\section{du Canada}

Direction des acquisitions et

des services bibliographiques

395, rue Wellington

Ottawa (Ontario)

K1A ON4
Your file Votre référence

Ourfile Notre réterence
The author has granted an irrevocable non-exclusive licence allowing the National Library of Canada to reproduce, loan, distribute or sell copies of his/her thesis by any means and in any form or format, making this thesis available to interested persons.

The author retains ownership of the copyright in his/her thesis. Neither the thesis nor substantial extracts from it may be printed or otherwise reproduced without his/her permission.
L'auteur a accordé une licence irrévocable et non exclusive permettant à la Bibliothèque nationale du Canada de reproduire, prêter, distribuer ou vendre des copies de sa thèse de quelque manière et sous quelque forme que ce soit pour mettre des exemplaires de cette thèse à la disposition des personnes intéressées.

L'auteur conserve la propriété du droit d'auteur qui protège sa thèse. Ni la thèse ni des extraits substantiels de celle-ci ne doivent être imprimés ou autrement reproduits sans son autorisation. 
Nam.

Dissertation Abstracts International is arranged by broad, general subject categories. Please select the one subject which most nearly describes the content of your dissertation. Enter the corresponding four-digit code in the spaces provided.

\section{Subject Całegories}

\section{THE MUMANITES AND SOCIAL SCIENCES}

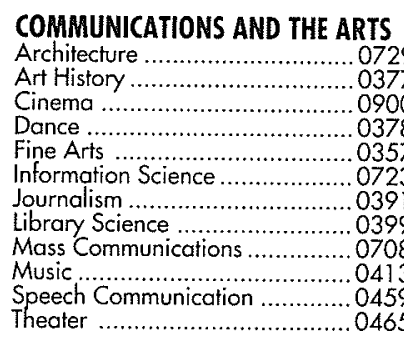

\section{EDUCATION}

General ...................................0515

Administration .............................05 4

Adult and Continuing .................0516

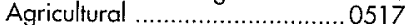

Art ........................................... 0273

Bilingual and Multicultural ..........0282

Business ................................0688

Curriculum and Instruction ..........0727

Early Childhood ........ 0518

Elementary ............................. 0524

Finance ..................................... 0277

Guidance and Counseling ............0519

Health ................................ 0680

Higher ................................. 0745

History of ........................... 0520

ndustrial .

Language and Literature ............... 0279

Mathematics .......................... 0280

Music ......................................... 0522

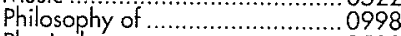

Physical ...................................... 0523

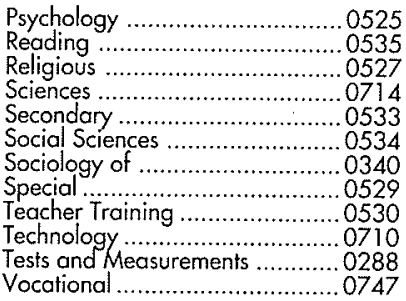

\section{LANGUAGE, LITERATURE AND} LINGUISTICS

Language

General ...........................0679

Ancient ................................... 0289

Linguistics ......................... 0290

Modern

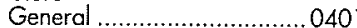

Classical ................................029

Comparative ........................... 0295

Medieval ..............................0297

Modern ............................... 0298

African ................................. 0316

American ..........................059

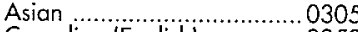

Canadian (English) ............... 0352

Canadian (French) ..............0355

English ............................ 0593

Germanic .......................... 0311

Latin American ...................0312

Romance ............................0313
Slavic and East European .....0314

\section{TME SCIENCES AND RNGINERTING}

\section{BIOLOGICAL SCIENCES}

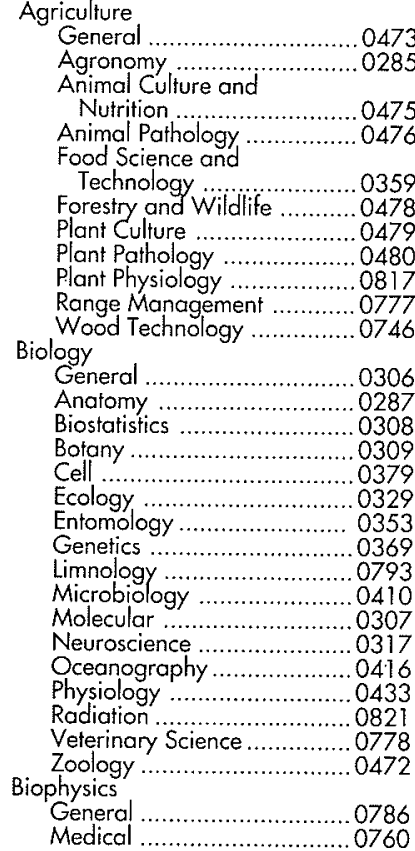

EARTH SCIENCES

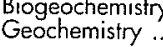

Geodesy ............................... 0370

Geology ................................ 0372

Geophysics ................................. 0373

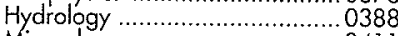

Mineralogy ........................... 04 J 1

Paleobotany .......................... 0345
Paleoecology

Paleontology ........................ 0418

Paleozoology ........................ 0985

Palynology ........................... 0427
Physical Geography ...............0368
Physical Oceanography ...........0415

\section{HEALTH AND ENVIRONMENTAL}

SCIENCES

Environmental Sciences ............0768 Health Sciençes

General .............................0566

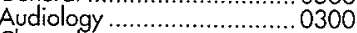

Chemotherapy ..................... 0992

Dentistry .............................. 0567

Education ............................. 0350

Hospital Management ..........0769

Human Development .............0 0758

Immunology ..........................0982

Medicine and Surgery ..........0564

Mental Health .................... 0347

Nursing ............................ 0569.

Nutrition ............................ 0570

Obstetrics and Gynecology .. 0380

Occupational Health and

Therapy ..........................0354

Ophthalmology .......................0381

Pathology ................................ 0571

Pharmacology ...................... 0419

Pharmacy ......................... 0572

Public Health .........................0573

Radiology ............................ 0574

Recreation ...........................0575
SUBJECT CODE

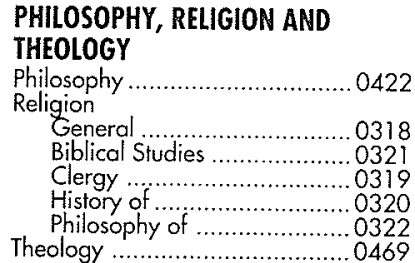

SOCIAL SCIENCES

American Studie

Anthropology

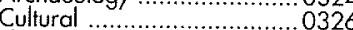

Physical ....................................... 0327

Business Administration

General .........................0310

Accounting ..................... 0272

Banking ......................... 045

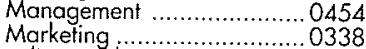

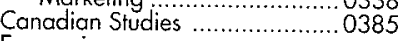

Economics

Agricultural ............................... 0503

Commerce-Business .............. 0505

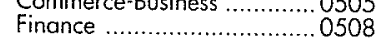

History ...................................0509

Labor ................................ 0510

Folklore

Geography

0511

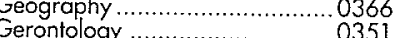

History

General

.0578
Archaeology ......................0324

General ..........................050

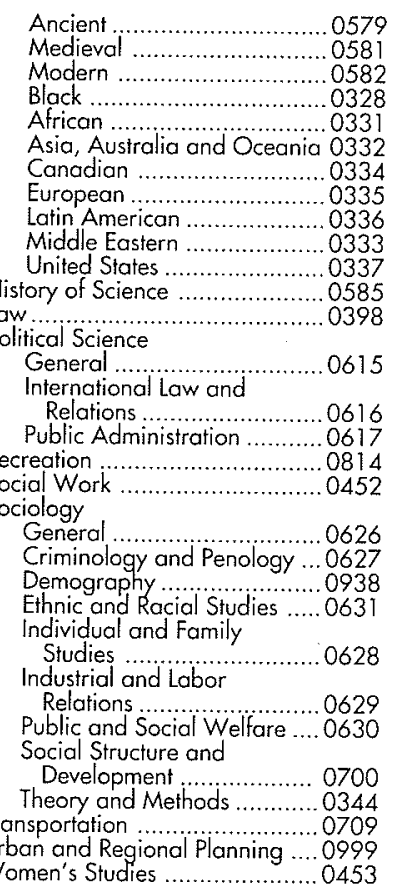

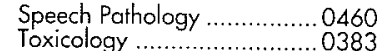

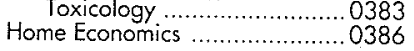

\section{PHYSICAL SCIENCES}

Pure Sciences

Chemistry

General ...........................0485

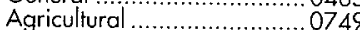

Analytical ..........................0486

Biochemistry .......................0487

Inorganic ........................... 0488

Nuclear ................................... 0738

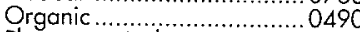

Pharmaceutical .......................0491

Physical ............................... 0494

Polymer .............................. 0495

Mathematics ............................. 0405

Physics

General ...........................0605

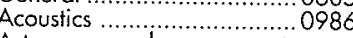

Astronomy and

Astrophysics ...................0606

Atmospheric Science............. 0608

Atomic ..........................0748

Electronics and Electricity .....0607
Elementary Particles and

High Energy .................... 0798

Fluid and Plasma .....................0759

Molecular .............................0609

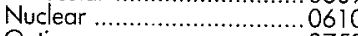

Optics ............................... 0752

Solid State ........................ 0756

Statistics ................................... 0463

Applied Sciences

Applied Mechanics ................. 0346

0984

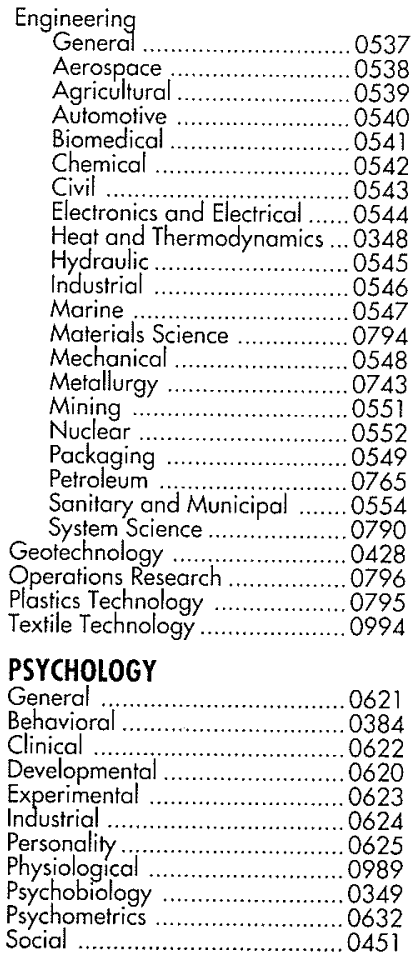

8 
ANNE RATZ

A Thesis submitted to the Faculty of Graduate Studies of the University of Manitoba in partial fulfillment of the requirements of the degree of

\section{MASTER OF NURSING}

(C) 1995

Permission has been granted to the LIBRARY OF THE UNIVERSITY OF MANITOBA to lend or sell copies of this thesis, to the NATIONAL LIBRARY OF CANADA to microfilm this thesis and to lend or sell copies of the film, and LIBRARY MICROFILMS to publish an abstract of this thesis.

The author reserves other publication rights, and neither the thesis nor extensive extracts from it may be printed or other-wise reproduced without the author's written permission. 
Contents

\begin{tabular}{|c|c|}
\hline & $\mathrm{Pa}$ \\
\hline Ahstrast & 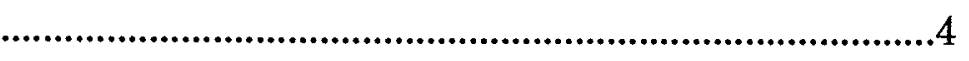 \\
\hline Acknowle & 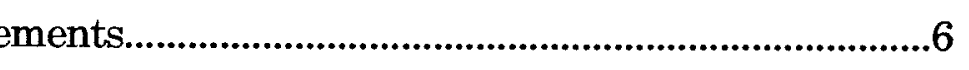 \\
\hline ListofFigl & 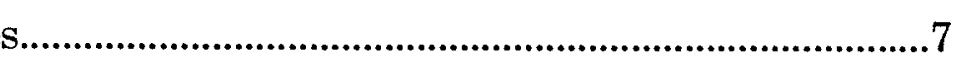 \\
\hline Chapter & \\
\hline 1 & Statement of the Problem........................................8 \\
\hline & Introduction \\
\hline & Uncertainty in HIV Infection...............................11 \\
\hline & 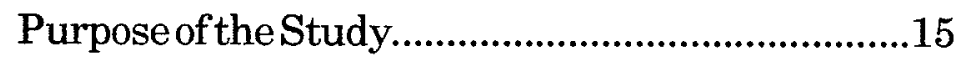 \\
\hline & 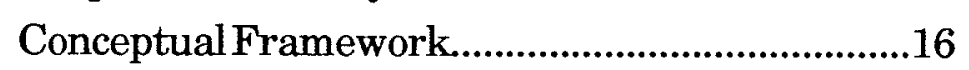 \\
\hline & 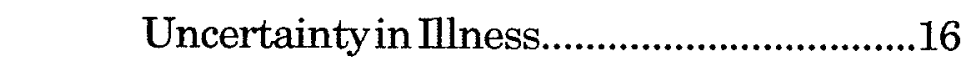 \\
\hline & Uncertainty in Chronic Mlness..................22 \\
\hline & 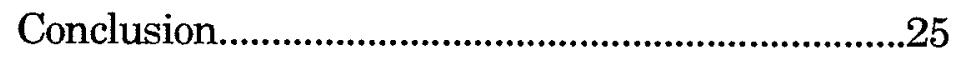 \\
\hline 2 & Review of the Literature....................................26 \\
\hline & Introduction \\
\hline & 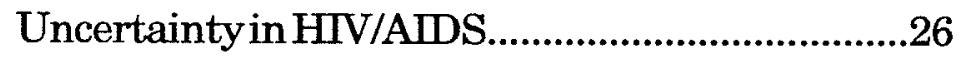 \\
\hline & Uncertainty in Other Hlness...................................31 \\
\hline & Uncertainty in Life-threatening Illness................38 \\
\hline & 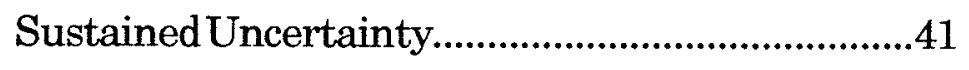 \\
\hline & Responses to HIV Infection.....................................43 \\
\hline & 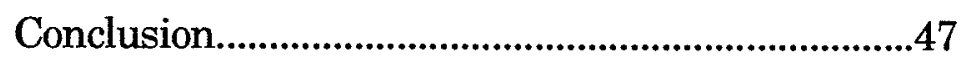 \\
\hline 3 & 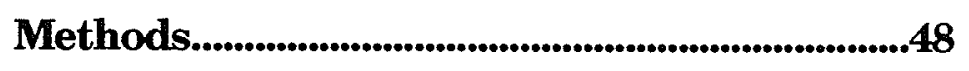 \\
\hline & 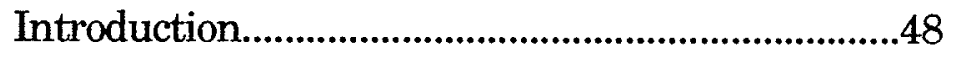 \\
\hline & Subjects and Recruitment Procedure..................48 \\
\hline & 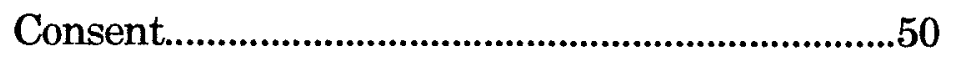 \\
\hline & 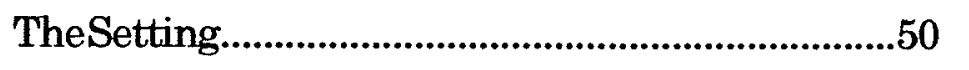 \\
\hline & Instrument \\
\hline & 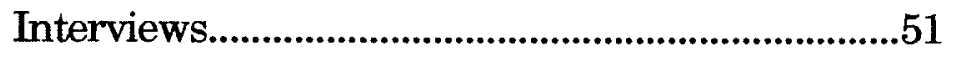 \\
\hline & Confidentiality......................................................52 \\
\hline & 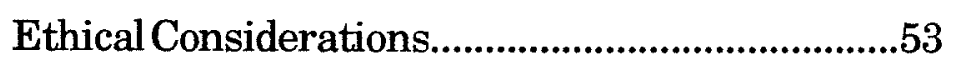 \\
\hline
\end{tabular}




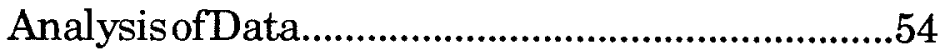

Validation ofData..................................................56

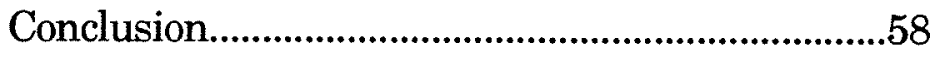

4 Narratives.......................................................................59

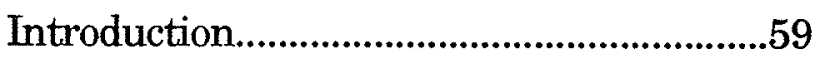

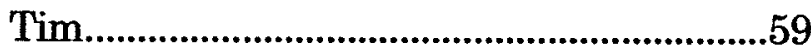

Stan

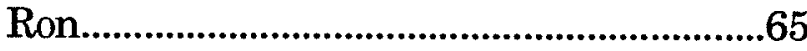

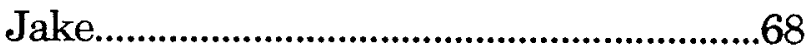

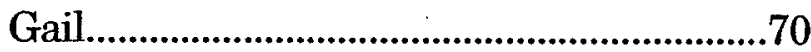

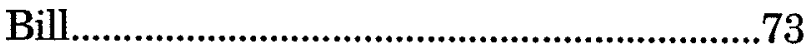

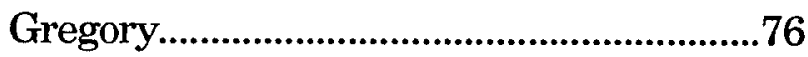

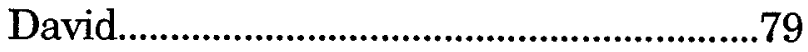

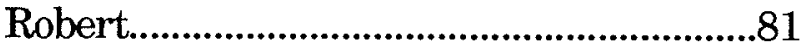

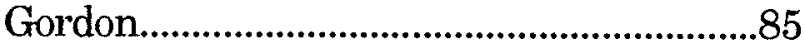

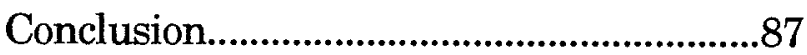

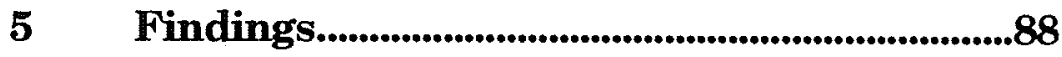

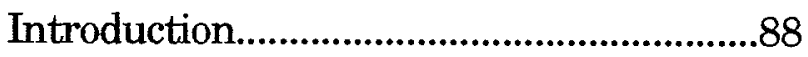

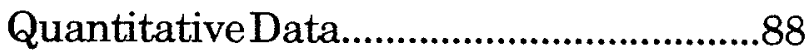

QualitativeData..........................................90

Thematic Analysis.........................................93

Introduction..........................................93

Developing a New Perspective......94

Surviving the HIV Diagnosis.........96

Taking Care........................................101

Living in the Present.......................111

Seeking Support..............................116

Appreciating the Positive...............121

Trustworthiness...........................................126

Reflection and Reflexivity...........................127

Conclusion......................................................129 
6 Discussion...........................................................................131

Introduction...................................................131

Methodoligical Issues.....................................131

Theoretical Issues.........................................134

Implications for Research..........................140

Implications for HIV Infected Individuals...........................................141

Implications for Nursing Education and Practice.........................................143

Conclusion.......................................................145

References...................................................................146

Bibliography..................................................................152

Appendices..............................................................................153 


\section{Abstract}

HIV infection has affected the lives of tens of thousands of Canadians over the past fourteen years. It continues to impact significantly on the lives of those infected and also on the lives of those affected.

Despite progress in therapies and gains in knowledge about transmission and prevention, much is still to be discovered about this virus. The experience of those infected with the virus is one of enormous upheaval and disruption of daily living and long term plans. Central to this experience is vague disease symptomatology, changing medical management, and varied responses of social contacts.

This combined quantitative/qualitative study explored the experience and consequences of uncertainty in the lives of people with HIV infection. Uncertainty was measured in a convenience sample using the Mishel Uncertainty in Illness Scale (community form). Indepth focused interviews with ten individuals were conducted to describe the consequences of uncertainty.

It was found that, within the context of uncertainty, individuals living with HIV infection form a new perspective on life. Central to this phenomenon are five core experiences. Each core experience comprises a number of actions which are used by the individual to formulate and maintain the new perspective on life.

It is hoped that the findings of this study will increase the body of knowledge about HIV infection. As well, the information obtained in this 
study may guide nursing practice and education in the future by providing insight into the lived experience of those infected as well as generate ideas for future research. 


\section{ACKNOWLEDGEMENTS}

This research has been a joy from conception to completion, in no small part due to the many individuals who have touched my life as a student and nurse.

The members of my thesis committee, Dr Linda Kristjanson, Dr Elizabeth Hansen, and Dr Deborah Dudgeon, have graced me with the freedom to follow my instincts and have inspired me with their confidence in me as fledgling researcher.

My family have blessed me with their patience and acceptance of my moods and possession of the computer. My husband Alan is the sun around which my life revolves, my mother Pauline the moon who stands in silent support. My children, Ayli and Zak, are the brightest stars who light up my galaxy, every night and every day.

The men and women who gave generously of their time and energy to answer my questions and participate in this project have a special place in my heart. I have learned so much from them about living with HIV and relating to others with honesty and integrity.

This thesis is dedicated to the memory of those for whom the cure did not come in time. Each of them has touched my life and led me to the place where I am now. When it is my time to leave this planet, I know they will be waiting to help me make the transition to another state of being. 


\section{LIST OF FIGURES}

Page

1. Mishel's Uncertainty in Illness Theory.............................16

2. Proposed Changes to Uncertainty in Dlness Theory......24

3. Scores on Uncertainty in Illness Scale...............................90

4. Description of Participants...................................................91

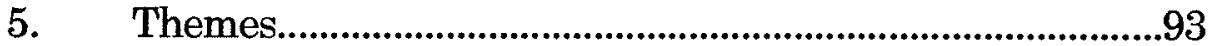


CHAPTER ONE

\section{STATEMENT OF THE PROBLEM}

Introduction

In the early 1980 s the emergence of an apparently new disease among homosexual and bisexual men captured the attention of the medical profession and the general public. Young men were presenting with unusual symptoms and opportunistic infections usually seen in patients with severe immune suppression. This syndrome was initially described as Gay Related Immune Deficiency (GRID) (Shilts, 1987 p. 121) and ultimately as Acquired Immune Deficiency Syndrome (AIDS) (Shilts, 1987 p.171).

All who showed signs of immune suppression died; many were diagnosed with Pneumocystis carinii pneumonia or a rare form of skin cancer, Kaposis sarcoma. Others were found to be infected with avian and other animal bacteria and viruses. In 1983 a retrovirus was isolated from the serum of these individuals and eventually named the human immunodeficiency virus (HIV) (Shilts,1987 p. 593). Shortly thereafter a screening test was developed which detected antibodies to the virus. It was predicted that a vaccine would soon be developed to protect the uninfected as well as prevent progression to AIDS.

As young men died in hospitals throughout North America of unusual and virulent forms of infection, a great deal of uncertainty and fear was generated among homosexuals, the medical community, and the general public. The appearance of HIV and AIDS in predominately 
9

homosexual and bisexual men became the flash point for discrimination and talk of a "Gay Plague" (Shilts, 1987. p 352). Very little was known about this disease, including mode of transmission and no effective treatments were available.

More than ten years later a vaccine has not been developed. Most, if not all, HIV infected individuals at this point in time will eventually develop AIDS and die. This virus has been the cause of death of almost 7000 Canadians thus far (Health Canada, 1994) and 441 Manitobans have tested positive for antibodies to the virus (Manitoba Health, 1994). However, medical therapy has improved and many individuals are living longer before progressing to AIDS.

Over the ensuing years, progress has been made on many issues. The mode of transmission is well established ; sexual intercourse without condoms, sharing of needles for injection of recreational drugs, contaminated blood products, and vertical transmission from a pregnant woman to her fetus are the major routes of infection (Cohen, 1991). Prophylaxis and treatment of opportunistic infections have become more effective and a variety of anti-retroviral drugs are able to prevent viral replication within the human body for variable periods of time (Volberding, 1990a). However, no drug exists which can prevent the eventual destruction of the immune system which ultimately leads to death.

Psychosocial responses of individuals with HIV infection embody a wide range of emotions including shock, denial, anger, depression, hope, 
restructuring of goals, and changes in lifestyle (Gaskins \& Brown,1992). Studies have described the experience of uncertainty in the lives of those infected (Siegel \& Krauss, 1991) and affected (Brown \& PowellCope,1991) by this disease. Much of this uncertainty is concerned with the unpredictable nature of this disease, from the long asymptomatic period following infection to the often vague and confusing symptoms associated with opportunistic infections.

In Western society today there is emphasis placed on the predictability of life. This expectation extends into medicine and individuals expect that a cause for their illness will be determined and control or cure attained. Illness is seen as disequilibrium and the goal of medical and nursing interventions is to restore equilibrium. Uncertainty is inherent in illness. Anyone experiencing illness deals with uncertainty as they are confronted with new physical symptoms, treatment choices, unfamiliar systems of care, lack of information about the illness, and unpredictability of the course of the disease.

Mishel's Uncertainty in Illness Theory (Mishel,1988) explains how people process illness-related events and construct meaning from these events. This theory has been reconceptualised to include those suffering from chronic and life-threatening illness (Mishel, 1990a). This reconceptualization proposes that individuals experiencing overwhelming and continual uncertainty can change their perspective of life and develop a new and more complex orientation toward life.

The extent to which those infected with HIV react to continual 
uncertainty has not been reported in the literature. Through professional contact with many individuals with HIV, this researcher has heard some of them say that having HIV turned their lives around and that they did indeed gain a new perspective and attitude towards life.

\section{Uncertainty in HIV Infection}

Although studies have shown that uncertainty exists in the lives of those infected (Siegel \& Krauss, 1991 ; Tross \& Hirsch, 1988), the end result of the long term uncertainties facing these individuals is not well described. One study by Weitz (1989) describes uncertainty in the lives of people with AIDS ; these individuals are reported to experience uncertainty regarding the meaning of symptoms and the extent to which future functioning will be impacted by the disease process. However, the issues facing people with HIV infection as opposed to an AIDS diagnosis may well be considerably different and in the years since Weitz's study, many changes in care and treatment have occurred. It is therefore the intention of this study to explore the consequences of long term uncertainty in an effort to articulate the experiences of people with HIV infection and to give direction for nursing education and research.

Those living with HIV infection face a multitude of problems. Despite the early predictions of scientists, no effective cure exists for the disease and there is still a great deal that is not known or is in the process of being discovered. Some individuals with HIV infection feel that they have to inform themselves about new developments in 
treatment in order to inform their physicians. In smaller cities, it may be difficult to find physicians who are knowledgeable about HIV infection (Bartlett \& Finkbeiner, 1991).

The natural history of HIV disease is comprised of a number of stages (Volberding \& Cohen, 1990). As the infected individual progresses through the stages, he/she may experience uncertainty related to diagnosis, disease progression, treatment issues, and psychosocial responses.

After the virus enters the bloodstream it begins to replicate in macrophages and CD4 lymphocytes. At this time the infected individual may experience an acute flu-like illness but many people ignore this or think they simply have the flu. After this initial inoculation, viral replication appears to slow down and it may be years until further immune suppression occurs.

Uncertainty may exist for the individual who suspects he/she is infected but is fearful of being tested. The period between having the test and receiving the results is one of high anxiety. Some individuals question the sensitivity of the test itself (VanDevanter, 1991). A positive test precipitates a crisis for most individuals and in the ensuing weeks and months the individual must deal with a multitude of questions, new information and demands for making disclosure and treatment decisions (VanDevanter, 1991). One frequently observed response is the "time bomb" effect as the individual questions when he/she will become sick (Strawn,1991). These responses may continue 
over months and years during the latent phase of the illness (Volberding \& Cohen, 1990). Feelings common in the first one hundred days after diagnosis of a life threatening illness include preoccupation with mortality, a sense of personal vulnerability, and heightened emotional distress (Tross \& Hirsch, 1988).

When viral replication occurs, CD4 cells are destroyed and this eventually causes the devastating immune suppression associated with advanced HIV infection. In the early stages of immune system decline, constitutional symptoms are noted including generalised lymphadenopathy, weight loss, diarrhoea, night sweats, and fever (Volberding \& Cohen, 1990).

Media reporting in this stage may be a source of great uncertainty for people with HIV infection. Results of drug research are often reported in newspapers and magazines or by television news; these reports are generally sensationalistic and raise the hopes of those infected. Often the reports are based on early in vitro testing and further testing shows no benefit or severe side effects. Drugs that show initial promise are often found to be ineffective and the results of clinical trials may take many months to be released. Resistance of the HIV virus itself to established medications may develop after a few years of use (Volberding, 1990b).

Variations in disease trajectory may be a source of uncertainty. While some infected individuals remain healthy for extended periods of time, others experience rapid disease progression. In the last five years, 
increasing numbers of women have become infected and they progress more rapidly than men and indeed have different disease manifestations (Poole, 1990). Women with HIV infection may in fact remain undiagnosed as they may not suspect they have been exposed to the virus and their physician may not link their symptoms to those of HIV infection (Berer, 1993).

Rare opportunistic infections may develop in immune suppressed individuals and diagnosis as well as treatment may be delayed due to atypical or unusual presentation. Thus vague and complex symptomatology may increase the experience of uncertainty for the infected individual. An example of this is the increasing numbers of acute cases of tuberculosis that have been reported in the past five years as well as a large increase in the incidence of reactivation of latent infection (Schechter, 1990).

Disclosing one's HIV status is some cases means disclosing one's sexual orientation or recreational drug use. Some people have reported being shunned by family and friends (Laryea \& Gien,1993; Siegel \& Krauss,1991) while others have received support. Fear of losing housing, employment, and insurance benefits may play a role in disclosure. Deciding when and to whom to disclose is a major source of anxiety for many with HIV infection. Issues of disclosure and stigma may thus cause uncertainty about the level of social and emotional support available to the infected individual.

Individuals react to uncertainty in a variety of ways. Mishel 
(1988) contends in her original theory of Uncertainty in Illness that adaptation occurs as a result of coping mechanisms employed to deal with a state of uncertainty. Adaptation is viewed as a neutral zone which allows for goal-directed behaviour while activation of coping mechanisms continues. If difficulties with adaptation occur, activation of coping mechanisms will continue at a higher than normal level for that particular individual.

However, reconceptualization of the theory looking at chronic or life-threatening illness (Mishel, 1990) points to an inability on the part of the individual to adapt to continual or repeated uncertainty and the end result may be the development of a new and more complex perspective of life which is in fact evidence of growth.

Purpose of the Study

It is the purpose of this study to explore the extent to which uncertainty exists in the lives of people with HIV infection and the consequences of this uncertainty.

The research questions to be asked are :

1. To what extent does uncertainty exist in the lives of people with HIV infection in Winnipeg?

2. How is this uncertainty experienced by the individual?

3. What are the consequences of this uncertainty?

4. Do people living with HIV infection form a new perspective of life as a consequence of uncertainty? 


\section{Conceptual Framework}

\section{Uncertainty in Illness}

According to Mishel (1988), uncertainty is defined as "the inability to determine the meaning of illness-related events." This theory attempts to explain how individuals cognitively process the many and varied events which occur in illness and find personal meaning in the situation. A diagrammatic representation of the theory is presented in Figure 1.

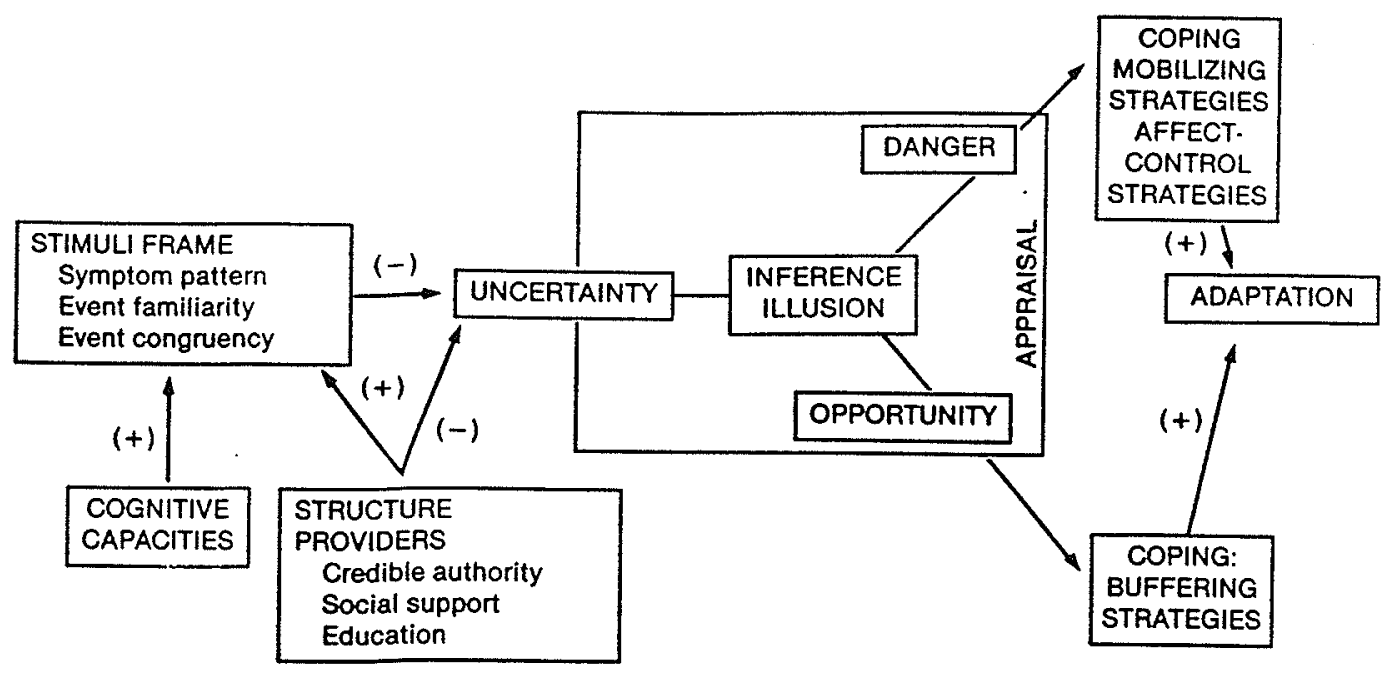

There are four phases in this theory. The first phase concerns the causes of uncertainty. Uncertainty is seen to be derived from the illness events; specifically the symptoms of the illness, how often they occur and how reliable in presentation they are. Mishel describes this triad as 
the stimulus frame. Symptom pattern refers to the presentation of symptoms; consistency in symptoms allows for meaning to be ascribed to them. Event familiarity describes how recognisable the pattern is and this too will allow for meaning to be attached. The consistency between what is expected in the illness and the actual experience is referred to as event congruence.

In HIV infection, symptoms are often vague and occur sporadically. Symptoms may also differ from one individual to another so that comparison is difficult and event familiarity does not lessen the uncertainty. Many gay men have seen friends and lovers die of AIDS and they may expect the same manifestations of illness in themselves. When this does not happen, event congruence is lessened and uncertainty is increased.

This stimulus frame is influenced by two variables - the cognitive capacity of the individual experiencing the illness and structure providers. The cognitive capacity is the amount of information that the individual is able to process at any given time. The structure providers are the resources available to the individual and encompass social supports, education level, and the amount of trust that the individual has in health care providers.

For those infected with HIV infection, cognitive capacity can be limited by information overload. Individuals may receive advice and opinion from many sources including friends, health care providers, the media and other people with HIV infection at formal and informal 
support groups. In addition, during the initial stage around diagnosis, many individuals are unable to process information because they are in an emotional state and experiencing shock, numbness and distress (VanDevanter, 1991).

For many individuals with HIV infection, the structure providers as defined by Mishel (1988) may be absent. Many gay men have been estranged from their family of origin for years and may have lost many friends to AIDS over the past 14 years (Strawn, 1991). The age group most commonly affected by HIV infection, those in their twenties, thirties and forties, have usually not accessed the health care system much and may take some time to develop trust in health care providers.

An individual will process the illness-related events to construct a cognitive schema or meaning for him/herself from the experience. If this cannot be done, uncertainty will result. Mishel (1988) contends that in illness, uncertainty presents in four forms : ambiguity about the illness itself, issues relating to the complex nature of treatment and the health care system, lack of information about the illness itself and its seriousness, and the unpredictable nature of the disease itself and its prognosis.

The experience of HIV infection meets these criteria. During the asymptomatic early stages of infection, it is difficult for many to accept that they are indeed infected with the virus. Treatment of this condition is never static with new medications and treatment regimens being tried by physicians and researchers. New manifestations of the disease are 
frequently reported in the medical literature and then in the lay press generating uncertainty among those infected as to whether they are receiving the latest and best treatment. Some infected individuals appear hypochondriacal as they question minor physical ailments and conduct self examinations for signs of disease progression (Strawn, 1991).

The second phase of the model, that of appraisal, is defined as a response to the presence of uncertainty in the life of an individual. Uncertainty is appraised by the processes of inference and illusion. People use inference in ambiguous circumstances and cues for inference originate both externally and internally. Internal cues are likely to be related to locus of control while external cues may come from information provided by people in the environment such as family or health care providers.

The end result of appraisal using inference is that of seeing the uncertainty as a danger and the individual recognises the possibility of a harmful outcome.

HIV infection is often described as a "death sentence" and the statistics available support this notion (Gee, 1988). The appraisal of this disease as a danger is common and probably realistic. However, uncertainty may persist due to the unpredictable nature of the disease trajectory itself and as Weitz (1989) describes, people remain uncertain about what opportunistic infections they may acquire or the circumstances of their dying. 
If illusion is used as part of the appraisal process, the result is that of viewing uncertainty as an opportunity. This may be the way in which hope is maintained in life-threatening illness. Often family and health care workers aid the individual in the generation of illusions and thus seek to maintain hope and the perception that the uncertainty is indeed an opportunity rather than a danger.

Some individuals may view a diagnosis of HIV infection as much better than one of AIDS and may use the asymptomatic period to make lifestyle changes and use other "wellness" strategies such as exercise and good nutrition to prolong the asymptomatic stage for as long as possible (Bartlett \& Finkbeiner, 1991. p. 54).

The third phase of the model includes the coping mechanisms associated with an appraisal of uncertainty as danger or opportunity. Coping is directed at reducing uncertainty and managing the emotions associated with it. Two types of coping mechanisms are proposed when uncertainty is seen as a danger.

Problem focused coping is associated with information seeking, vigilance, and direct action. In HIV infection, problem focused coping may include dealing effectively and assertively with health care professionals and developing strategies to deal with living with a terminal illness (Gaskins \& Brown, 1992). If these strategies are not effective, emotion focused coping is used in an attempt to manage the anxiety inherent in the uncertainty. Ross, Tebble and Vilinias (1989) describe a state of withdrawal and depression in which infected 
individuals avoid contact with others in an attempt to avoid the reactions of others to their disease.

If the uncertainty is appraised as an opportunity, the individual will seek ways to maintain that uncertainty by using illusion to generate a more positive outcome. Essentially the individual concentrates on the positive aspects of the situation rather than the negative. In a situation where the only alternative to uncertainty is negative, uncertainty is preferable. Buffering is used to continue the uncertain state and includes avoidance of new information, selective ignoring of new input and sensations, neutralising any stimuli that may threaten the fragile state of optimism, as well as reordering priorities by making lifestyle changes. This buffering differs from denial in that denial involves complete blocking of the event as a defense to prevent decompensation (Ross, Tebble, \& Viliunas, 1989).

Individuals with HIV infection often attend support groups in an attempt to manage the emotions associated with living with a chronic infection. These support groups may also serve an educative function in that other group members bring ideas and information to the group (Bartlett \& Finkbeiner, 1991. p.260). However some individuals may avoid others who are infected in an attempt to deny the possibility of what may lie ahead in the future (Bartlett \& Finkbeiner, 1991. p. 254).

The final phase in the model is that of adaptation. In this phase, the individual makes physical, emotional, and social changes to their behaviour patterns. When adaptation takes place, the individual is able 
to continue his/her life effectively.

This theory contends that uncertainty disrupts an individual's sense of control and this leads to disequilibrium. Adaptation is thought to occur and restore equilibrium. But this does not take into account the experience of individuals with chronic or life-threatening illness in whom constant fluctuation of health status is the norm.

\section{Uncertainty in Chronic Illness}

It is common in chronic illness for uncertainty to affect many aspects of life and it essentially cannot be contained in any one sphere. Uncertainty may also multiply rapidly and move the individual past a critical point where stability is no longer possible. Uncertainty in one area of the illness may also feed back on itself generating further uncertainty. This uncertainty can break down any cognitive structures that the individual has built in the past and confusion and disorganisation result with the end result being loss of meaning.

Mishel (1990a) has reconceptualised the theory of uncertainty in illness in an attempt to explain the unique experiences of managing sustained uncertainty in the face of chronic or life-threatening illness. Depending on the length of time that the uncertainty is present and the level of uncertainty, the individual may change the existing perspective of life to a new more complex one.

This new state is influenced by the individual's prior life experience, physiological status, social resources, and the attitudes of health care providers working with the individual. 
The process is theorised to take place by a gradual approximation of a previous negative appraisal to an opportunistic one. Individuals are thought to integrate the experience of chronic uncertainty into the new reality they have created. Uncertainty is used to reformulate a view of life. This view of life is based on conditional thinking and is probabilistic. This new perspective of life can be maintained if social supports and health care providers support a probabilistic view and acknowledge that uncertainty exists.

Some individuals who are faced with sustained uncertainty may be unable to reformulate their life perspective. Barriers to the process include negation by social supports of a probabilistic view or individuals who are isolated from others and are unable to obtain affirmation for their new view of life. If health care providers caring for the individual maintain a persistent search for predictability and certainty about the illness, it may not be possible for the individual to successfully maintain a new perspective. As well, if the person experiencing a chronic or lifethreatening illness is the primary care giver of significant others, his/her response to the uncertainty may be delayed which may prevent formulation of a new world view. Mishel (1990a) contends that the result of blocking this reformulation of a life perspective may include symptoms similar to those experienced in post traumatic stress disorder including psychic numbing and uncontrollable and distressing thoughts.

To date, no empirical evidence has been published to support this new conceptualisation of uncertainty in illness. A diagram of 
Mishel's Uncertainty in Illness model follows in Figure 2 with proposed changes to allow for the reconceptualization.

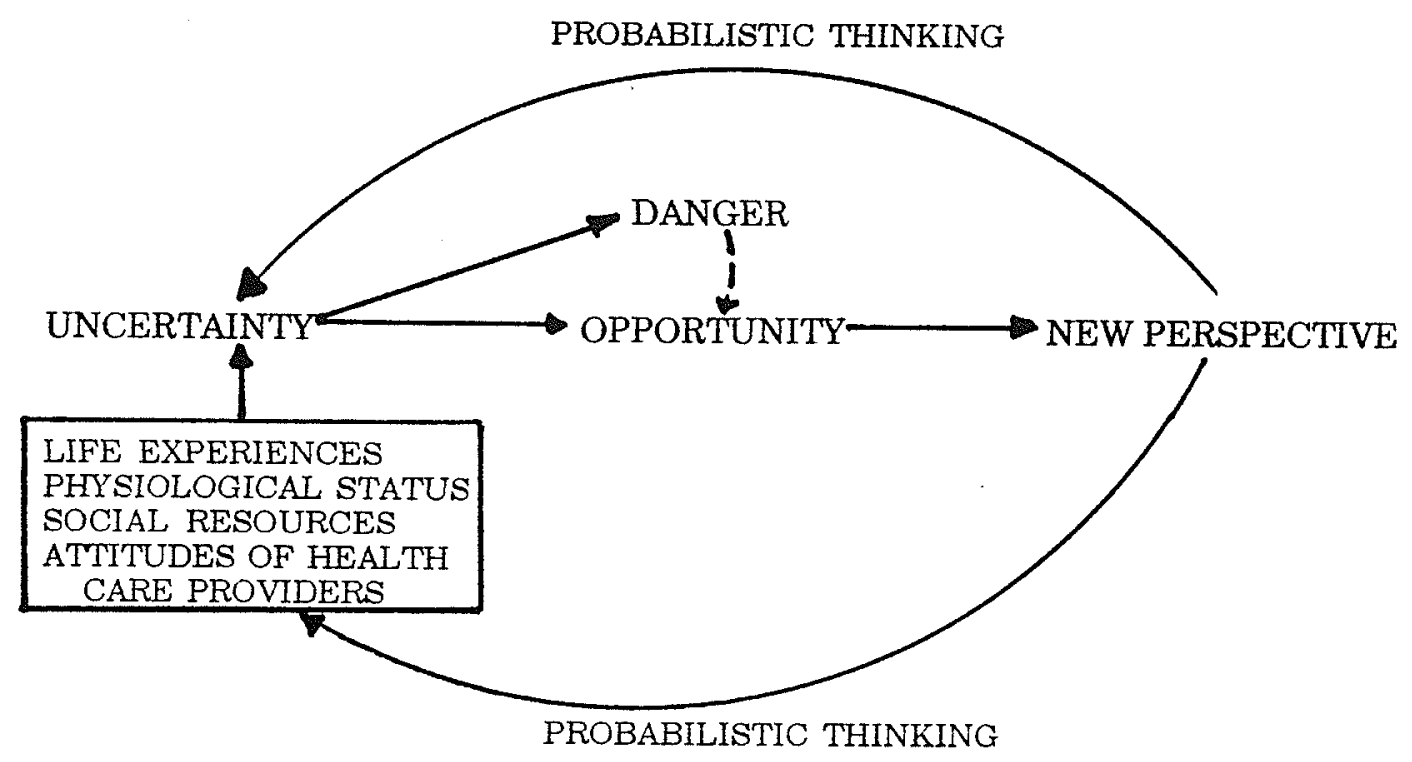

Figure 2. 
Conclusion

This chapter has highlighted the unique nature of HIV infection and the experience of those infected as they progress through the disease trajectory.

Mishel's Uncertainty in Tllness theory (1988) can be used to conceptualise the responses of the individual as this disease trajectory is negotiated by those infected. The reconceptualization of this theory as proposed by Mishel (1991) encompassing the experience of chronic illness remains untested at this date.

It is the purpose of this study to examine the consequences of continual uncertainty in those infected with HIV and in this way to test Mishel's reconceptualization of the theory. 
CHAPTER TWO

\title{
REVIEW OF THE LITERATURE
}

\author{
Introduction
}

This chapter will describe the findings of studies which have examined aspects of uncertainty in the illness experience. There have been no published studies to date of uncertainty in HIV infection. However, a number of studies have examined various aspects of uncertainty in other diseases. Studies which have examined the response of the individual to living with HIV infection will be described, in particular those relating to the experience of self-transcendence.

Uncertainty in HIV/ AIDS

There is one study to date regarding uncertainty in the lives of people with a confirmed AIDS diagnosis. This study by Weitz (1989) involving 23 gay and bisexual men indicated that these individuals experienced uncertainty in various ways during the illness. This qualitative study took place in 1986 and 1987 and at the time of the first of two interviews, many of the subjects had not yet been tested for antibodies to the virus. The overwhelming fear for these individuals was that they would be diagnosed with AIDS and the response to this was to develop personal theories for themselves about their relative risk based on past sexual activity.

They also experienced uncertainty regarding the meaning of physical symptoms and many avoided seeking medical care for fear of being diagnosed with AIDS. They preferred the uncertainty about the 
source of their symptoms to the reality of a positive ADS diagnosis. A related coping strategy to the uncertainty involved was their approach to the future. They would avoid making plans to reduce the risk of disappointment.

Issues of living with dignity and the fear associated with diminished mental functioning and the manifestation of Kaposis sarcoma affected these individuals. Joining support groups and seeking information was a strategy used to reduce fear. Some also fought to maintain unrealistic images of the future to quell anxiety.

Many believed that they could "beat AIDS"; they searched for actions that could preserve and improve health, for example by altering lifestyle patterns. The issue of dying with dignity and fear of physicians prolonging life was dealt with by many signing Living Wills and some making plans for suicide.

Weitz conducted a second interview with 11 of the original subjects four to six months later. At this time, they were learning to live with AIDS and uncertainty had become part of everyday life. The focus was now on living for the present. These men had learned to assert control in some aspects of their lives and in this way had decreased some of their stress.

Results of this study are limited for a number of reasons. Firstly, the respondents were all gay and bisexual men. Uncertainty may be experienced differently by women who may not recognise they have been at risk for HIV infection. Heterosexuals may have to contend with 
more uncertainty due to the lack of social supports in a society that in the past has seen a low prevalence of HIV among non-homosexuals. Many support groups have members who are predominately gay or bisexual and heterosexual men and women may not feel comfortable in such groups. These individuals may also find it more difficult to disclose their HIV status; they may be anxious that disclosure would raise issues about their sexual orientation or may identify them as injection drug users. In addition, the small sample size in this study results in a lack of generalisability.

The major criticism of this study is that the context within which the study was conducted has now changed. Since 1987 a range of antiviral therapies have become available that, while still not effective as a cure, have enabled people to live longer with HIV infection. Prophylaxis of opportunistic infections is more effective today and people are being tested for HIV infection years before they develop an AIDS defining illness.

The effect of HIV infection on the functioning and roles of family members has also been found to relate to the experience of uncertainty. Brown and Powell-Cope (1991) developed a theory of ATS family care giving in which uncertainty was identified as the basic social psychological problem and the core category leading from this was described as "transitions through uncertainty". This study focused on the perceptions and experiences of fifty three family care givers of people with ADS. 
Five care giving sub-categories were identified. The care givers described managing and being managed by the illness, living with loss and dying, renegotiating the relationship with the person with AIDS, going public with the disclosure of the illness in a loved one, and containing the spread of HIV within the care giving situation.

Individuals with HIV infection described many of the same experiences when studied by researchers. A qualitative study by Gaskins and Brown (1992) of the psychosocial responses of ten gay and bisexual men with HIV infection reveals that their intitial response was one of shock, anger, and fear of the future. A core category of "fighting to survive with HIV infection" was identified. Supporting concepts were those of "taking care" which encompassed everyday work and illness work, and "restructuring life" which included dealing with uncertainty, experiencing changing feelings, accepting homosexuality, protecting confidentiality, dealing with health professionals, handling multiple losses and eventually living with terminal illness.

Another study identified many similar issues. Siegel and Krauss (1991) identified three issues from a qualitative study on the adaptive tasks of HIV positive gay men. These fifty five gay men described having to deal with the possibility of a curtailed life span. They expressed an urgency to attain life goals and a need to weigh the extent to which they should invest in the future. These men also had to deal with reactions of others to their illness which is often stigmatising. This raised the issue of disclosure to others as well as a need to confront 
personal feelings of shame and contamination. The final issue according to this study is that of developing strategies for maintaining physical and emotional health. The men described a need to take control of their own health, to be vigilant about symptoms, and to make decisions about when to seek treatment and which choices to make regarding treatment options. In all this they considered it important to also maintain emotional equilibrium.

A small Canadian study (Laryea \& Gien, 1993) of nineteen men and six women documents and expounds the role of stigma in the lives of people with HIV infection and the double stigma of homosexuality and HIV infection. In this study, disclosure issues were found to be of major importance to the HIV infected individuals interviewed. The fear associated with disclosing their status to family, friends, and thus the community as a whole, impacted strongly on their ability to cope with the diagnosis. Uncertainty about their lives was experienced in conjunction with intense fear of disclosure and rejection.

Uncertainty in HIV infection has been explored from the perspective of the infected individual as well as family care givers. It appears from the literature that uncertainty exists even before the diagnosis is made (Weitz, 1989) as well as in the daily experiences of those living with the disease (Gaskins \& Brown, 1992) and those taking care of them (Brown \& Powell-Cope,1991). Common themes emerging from these studies include learning to live with the disease and the work involved in this, dealing with a shortened life span, dealing with the 
reactions of others to the disease, and learning to interact with health care professionals and the medical system.

\section{Uncertainty in Other Illnesses}

Uncertainty has been studied in a wide range of illnesses. Most of these studies support the phases of Mishel's (1988) theory, however there remains a lack of testing of the reconceptualization of the uncertainty theory.

Results from Wiener and Dodd's (1993) study of one hundred cancer patients and their families, lend support for Mishel's (1988) theory. They found that people living with illness suffer uncertainties of time, body, and identity. This range of uncertainties lends support to the antecedents of uncertainty as described by Mishel (1988) as stimuli frame. Symptoms may be vague and without a discernible pattern which leads to uncertainty. Wiener and Dodd (1993) noted that these individuals had to define and redefine the illness and the changes in identity to cope with the uncertainty over time. This was accomplished by pacing activities of daily living, becoming professional patients, seeking reinforcing comparisons, engaging in reviews, setting goals, covering up lost functions and roles, finding a safe place to let down and acknowledge fears and uncertainty, choosing a supportive network, and taking charge.

Some of these strategies could be described as problem focused coping strategies. Pacing oneself, becoming an informed and assertive consumer of health care, joining support groups and learning to ask for 
support from friends and family, as well as taking charge of illnessrelated events are all action oriented tasks that may reduce uncertainty.

In this study, respondents reported some emotion focused coping strategies, such as finding a place to let down and engaging in reviews. These did not necessarily result in emotional distress but may have provided an outlet for emotions and a balance for problem oriented coping measures.

In an early study examining uncertainty in illness, Mishel (1984) found that uncertainty was correlated to stress. She studied one hundred patients in a Veterans Administration hospital and found that at the root of uncertainty was the patients inability to assign value to events in the illness experience. The illness experience is seen to be comprised of symptoms, treatment procedures, the technical environment and people associated with it, and assessment of the future. Events related to these areas may be vague, unpredictable, ambiguous, unfamiliar, inconsistent in occurrence, and the patient may have insufficient information about any of the factors. This study found a stronger correlation between ambiguity and stress $(\mathrm{r}=0.35 ; \mathrm{p}<.001)$ and a weaker correlation between unpredictability and stress $(\mathrm{r}=0.19$; $\mathrm{p}<.05)$.

Among the patients studied, those with serious illness had particular difficulty categorising illness related events. In such circumstances, individuals can interpret neutral events as being highly 
threatening and misinterpretation may lead to significant events being ignored and an inability to distinguish harmful stimuli from helpful ones. This early study of uncertainty in illness found that patients coped with uncertainty by vigilance and avoidance.

A later study by Mishel and Braden (1988) examined the precursors of uncertainty, specifically the ambiguity and complexity of symptoms and illness related events. In this study, sixty one women with gynaecological cancer were asked about their symptoms and the events classified by Mishel as structure providers, namely education, social support and credible authority. These women were found to experience ambiguity when remissions and exacerbations of symptoms occurred. However, in order for symptoms to be recognised they had to be distinguishable and prominent. This allowed the patients to modify some aspects of treatment and in that way gain some control. If the patient had prior experience of the event or symptom, uncertainty was reduced.

This study also found that those factors described as structure providers had both a direct and indirect effect on uncertainty. Patients rely on structure providers, for example social supports and health care providers, to interpret illness related events. This constitutes a direct effect. Indirect effects are experienced by the patient in the way structure providers help the patient to determine the pattern of symptoms and in that way uncertainty will either be increased or decreased. Uncertainty was found to be decreased when social supports 
provided affirmation of symptoms and when health care providers helped structure the meaning of illness-related events by providing information and education.

This study, while giving support to Mishel's theory is limited by the gender bias inherent in the selection of the sample. Women may differ from men in their willingness to seek assistance from social supports and health care providers and the nature of gynaecological cancer may influence the type of symptomatology experienced.

Kostbade Hughes (1993) found that women with breast cancer experienced the highest degree of uncertainty at the time of diagnosis. This was associated with new and ambiguous information about a potentially life-threatening illness and the expectation of the patient understanding the variety of treatment modalities available. This study of seventy one women seems to support the premise of uncertainty arising from ambiguity, but it is also limited in the exclusively female sample and by the fact that these were all women recently diagnosed with a life-threatening illness.

Bennett (1993) examined responses of eighty one individuals who had suffered myocardial infarcts in an effort to clarify the relationship between the illness experience and coping. Bennett found that perceived lack of social support increased uncertainty and this was related to more negatively toned emotions. Contrary to Mishel (1991), Bennett found that emotions were an outcome of the threat rather than a result of coping. 
The studies described thus far focus on sources or antecedents of uncertainty. Uncertainty was linked to ambiguity of symptoms and lack of salient cues relating to the symptoms, and the the effects of support from family and health care providers. The emphasis of these studies have thus served to illustrate the first phase of the Uncertainty in Illness theory.

Studies have been conducted which highlight the second phase of the theory, that of appraisal of uncertainty as danger or opportunity.

In a study of women with gynaecological cancer, Mishel and Sorenson (1991) and Mishel, Padilla, Grant and Sorenson (1991) explored the role mastery plays in the uncertainty model. Mastery is defined as the beliefs the individual has about the ability to act to mitigate the adverseness of an event and is thought to mediate the relationship between uncertainty and the appraisal of danger and opportunity (Mishel et al.,1991). Mishel and Sorenson (1991) found that mastery is a personality factor that is specific to a situation and is weakened under circumstances of uncertainty. They found that the mediating effects of mastery are strong when uncertainty is appraised as a danger. Coping strategies, either emotion- or problem focused , acted as mediators between the the perception of danger or opportunity and the emotional distress theorised to result from them. However, coping strategies were found to be weak mediators only.

Mishel et al (1991) found that among the severely ill women studied, a belief in the uncertainty as an opportunity may not be based 
on mastery, but rather on a faith in something that promotes optimism. These women used the coping strategies of "wishful thinking" and a "focus on the positive".

These three articles may be limited in their relevance as their population was composed of women with a life-threatening illness. A study of women with rheumatoid arthritis (Bailey \& Nielsen,1993) showed support for the relationship between uncertainty and appraisal of danger or opportunity. They found that women with high uncertainty were likely to appraise the situation as dangerous.

Three published studies have focused on the third phase of the theory, that of coping. Webster and Christman (1988) looked at uncertainty in a predominately male sample of patients following myocardial infarction. They found that uncertainty increased with the use of affective coping and that ambiguity was related to the use of affective coping strategies. These subjects attempted to use problem solving coping strategies despite a high level of anxiety and depression. These results may reflect gender differences in the type of coping strategies used and their relative effectiveness.

Redeker (1992) showed that following coronary bypass surgery, patients attempt to distance themselves from the situation and also attempt to use wishful thinking when they are unable to structure personal meaning in uncertain situations. These authors infer that avoidance and wishful thinking in the presence of uncertainty may serve a protective function, but may also impede the patient's ability to 
interpret meaning and cues from the internal environment. This lack of clarity in interpreting symptoms may increase the ambiguity and complexity of the situation which ultimately may increase the uncertainty. These patients were seen to eventually seek out information and social support in an attempt to reduce uncertainty.

The end result of uncertainty in illness according to Mishel's model (1988) is that of emotional distress. A 1988 study by Christman, McConnell, Pfeiffer, Webster, Schmitt and Ries showed that following discharge after hospitalisation for myocardial infarction, those individuals with greater uncertainty used fewer confrontive coping behaviours and reported lower levels of activity. This study found that information given to patients before discharge may have been too simplistic and did not reflect the probabilistic nature of medical treatment. This may have been a factor in the level of emotional distress found in these subjects.

The sources and appraisal of uncertainty and the resultant attempts to cope with a state of uncertainty described in these studies lend support to Mishel's theory of Uncertainty in Illness (1988). The studies have small sample sizes and are restricted by the limitations of either male of female subjects which restricts the ability to generalise. However, they do illustrate the components of the theory as described. 
Uncertainty in Life-threatening Mlness

For those with a life-threatening or chronic illness, uncertainty is related to feeling unsafe and being unable to make decisions. There may also be a sense of not being able to rely on others (Hilton,1992). Uncertainty is seen to limit a sense of control and to increase helplessness. When ambiguity is great, more inference is needed to appraise the situation and emotion focused coping is seen by this author to have detrimental effects. Hilton (1992) asserted that using emotion focused coping strategies can lead to denial, avoidance, anger, normalisation of the situation which is inappropriate and other maladaptive behaviours such as smoking and over eating. Choosing emotion focused coping strategies may also prevent problem oriented coping from occurring which may lead to excessive fear, worrying and anxiety as well as a tendency to dwell on the negative.

This article addresses some interventions that health care providers can use to assist those with chronic or life-threatening illness. All interventions should be based on the patient's individual perception of their disease and experience. As assessment of the patient's emotional state is useful before beginning to work with the individual in an effort to cope with the stresses inherent in living with chronic or lifethreatening illness. The principle is to help the individual accept events or attempt to cope with them. Health care providers and family members should understand that some uncertainty is acceptable because it may be used to foster and maintain a sense of opportunity. 
How much uncertainty is useful and how to support that level of uncertainty remains a crtitical question for health care providers.

Those with chronic and life-threatening illness must in some cases learn to live with sustained uncertainty. Cohen (1993) explored this phenomenon by studying the experiences of ten families in whom a child had been diagnosed with cancer. Cohen reported that parents pass from a stable pre-illness world into a reconstituted uncertain world after the child is diagnosed. The stage of rupture is described as one in which parents must learn new parenting behaviours and change existing values. Their expectations of life for themselves and their child are altered and they feel set apart from others. The stage of living with the sustained uncertainty is filled with stress and fear and these parents tend to create uncertainty to deny the truth and create a sense of certainty where none exists.

Cohen has identified six interactive strategies which parents use in an effort to cope. These include time management in which the parents live in the present. This has been found to alter social relationships with other parents who are able to make plans for healthy children. Social interactions are altered by issues of disclosure and attempts by the parents to limit information given to others. This inevitably affects the quality of relationships with others. Parents must manage information on a variety of levels; they must seek out information but at times must limit and modify that information. At times parents will discount the information they are given. Parents also 
manage the awareness of their situation by structuring cognitive strategies and by routinizing activities they must perform which relate to the illness of their child. Managing the illness by constant vigilance in the early stages and periodic monitoring in later stages is essential to early detection of complications and to maintenance of the treatment regimen. Finally, parents must manage the environment and in so doing, protect the child from physical and psychological harm. This protection may interfere with normal developmental needs of the child and may cause problems in the long term for both parents and child. The result of these strategies is the development of a reconstituted assumptive world which is vulnerable and tentative with new priorities and unique norms for the family.

The findings from this study confirm the sub-categories of tasks that the family care givers of people with AIDS identified (Brown \& Powell-Cope, 1991). Many of the issues are similar and are dealt with in similar fashion. According to Mishel (1988), relationships within the family are part of the mitigating category of providers of structure which impacts on the development of uncertainty in the illness experience. Thus the experience of uncertainty by family members may affect the illness experience of the HIV infected individual.

The major difference is the description in Cohen's study of a state of "rupture" upon learning of the diagnosis of a young child. The illness itself is experienced and described in much the same way whether the child is young or an adult. The parent must manage the disease itself, 
information needs and altered social relationships.

When viewing the Uncertainty in Illness theory in relation to lifethreatening illness, it is important to understand that under these conditions it may be difficult, if not impossible, for the individual to appraise the situation as an opportunity. However, as Hilton (1992) contends, some uncertainty may be preferable to maintain hope in the face of the harsh reality of certainty under these circumstances.

Sustained Uncertainty

How the individual with chronic or life-threatening illness manages sustained uncertainty remains unclear in the literature. Selder's (1989) Life Transition theory addresses the uncertainty experienced by many when learning of the diagnosis of a life-threatening illness. This theory supports Mishel's (1988) conceptual framework both in the causes of uncertainty as well as in the consequences.

Selder (1989) contends that uncertainty is affected by surrounding events and distortion of experiences. For example, uncertainty may be increased by the inadequacy of language to describe symptoms or events. This inability to effectively communicate to others can lead to isolation and without social support and validation, the individual is hampered in their ability to see things in perspective. This is consistent with Mishel's antecedents of uncertainty, specifically the influence of structure providers on the development of uncertainty.

Central to the theory of life transition is the idea of the need to create a new reality which entails relinquishing the existing one. Selder 
contends that it is important for the individual to acknowledge the irreversibility of the disrupted reality and to recognise the dimensions of the reality that is changed. The permanency of the change must be confronted and a new reality can be formulated based on expectations and the meaningfulness of new experiences.

According to Selder, uncertainty leads to vulnerability which leads to further uncertainty and this fragility may hamper the development of a new constant identity. Individuals with life-threatening illness may need to concentrate on the reality of the pre-diagnosis period in order that, with the passing of time, it can be relinquished. Certain events, called trigger events, may cause reactivation of memories that accentuate the irrevocable nature of the changed reality and help the individual to identify missed options. Through a realisation of the permanency of the changes uncertainty will be reduced and a new reality will be formed.

The Life Transition theory contends that individuals seek to reduce uncertainty in different ways. Information seeking is initially useful for this purpose but later additional information will raise uncertainty. The normalisation of behaviour through creating patterns of behaviour that mirror the standards of society will also reduce uncertainty. Barriers to this normalisation include side effects of treatment and symptoms that alter behaviour patterns. Testing personal competency, for example by attempting tasks that were previously successful, reduces uncertainty by making the individual feel 
sure about him/herself. Comparative testing in the form of relating to similar others at support groups may also reduce uncertainty. It is possible however that failure to successfully complete a challenge or unfavourable comparisons to others may increase uncertainty and impede the development of a new reality. Some individuals may minimise missed options by recognising what is possible and placing the loss in perspective. The practice of living in the present (one day at a time) may also serve to reduce uncertainty but may lead to loss of hope.

This theory highlights some interesting concepts in the resolution of uncertainty in the lives of those with life-threatening illness. It has been tested in studies of individuals with spinal cord injury and parents of infants with Down's Syndrome. However, like Mishel's reconceptualization of the Uncertainty in Nllness theory (1990a), more studies are needed to provide empirical support. Selder's (1989) theory was published before the reconceptualization of the Uncertainty in Illness theory by Mishel (1990a) and may indeed lend credibility to some of the untested premises of Mishel's theory.

Responses to HIV Infection

There have been numerous studies which have examined the responses of $\mathrm{HIV}$ infected individuals to living with this disease. A study by Allan (1990) of eleven homosexual men with HIV infection identified five dimensions of self-care activities. These include diet, exercise, stress reduction, life-style changes, and attitudinal adjustments. These selfcare activities were seen to enhance control, empowerment, and the 
belief in personal influence on health status. Initially attempts to initiate these activities were found to be chaotic but after a period of time, a few managable activities were identified through experimentation, information from health care providers, and consultation with family and friends. A difference was found between self monitoring and monitoring by professionals. The former was seen as a health maintenance activity while the latter was seen as illness related.

In a study by Benner Carson (1993), one hundred respondents completed the Personal Views Questionnaire as developed by Kobasa as well as a survey designed to elicit information about behaviours. Prayer and meditation as well as exercise and vitamin supplements were positively correlated with hardiness. Her study found little use of special diets in the sample. Fifty five percent of the sample had a case definition of AIIS which may have influenced the results as these respondents may have found the need for spiritual activities more important as they became sicker.

Kendall (1994) examined the concept of wellness spirituality in 29 homosexual men of whom 16 were diagnosed with HIV infection and 13 had a case definition of AIDS. In the context of this study, wellness was seen as spiritual rather than physical and was described as making sense of life and living life connected to what was most meaningful. Human connectedness was described as a need of these individuals and was achieved through six activities. They are belonging, sharing, gay bonding, confrontation, supporting, and touching. This connectedness 
was achieved through non-sexual means. Meaning in life was attained by reassessing priorites and becoming less materialistic and HIV infection was seen as an opportunity for growth.

Some nursing studies have examined the concept of selftranscendence. Reed (1991) defines self-transcendence as "the experience of extending one's self inwardly in introspective activities, outwardly through concerns about the welfare of others, and temporally such that the perceptions of one's past and the anticipated future enhance the present."

Coward and Marcus Lewis (1993) studied self-transcendence in gay men with AIDS and found nine themes from the interviews with these men. The first theme, experiencing several sources of fear, describes the fear of rejection and dying as related in the interviews. The second theme, taking care of oneself, relates to developing a positive outlook and maintaining health. Other themes include seeking out challenge which involves doing things previously avoided due to fear or self doubt, creating a legacy by wanting their lives to make a difference in the world, and accepting what cannot be changed. A theme identified as letting go describes relinquishing the ties to work as well as letting go of anger and self hate. The final three themes are described as connecting with others, accepting help, and having hope. The authors of this study suggest that these nine themes describe self-transcendence in that they meet Frankl's (1969) defintion of self-transcendence. The activities are seen to be giving to the world, taking from the world, and 
maintaining hope in the face of life-threatening illness. While this study is small with only eight participants, the description of the experiences of these men is rich and valuable. All the participants had a case definition of AIDS and had been diagnosed as such for between four and thirty one months. They appear to be quite ill in their description of themselves as able to perform daily activities with some effort. This may influence the findings of the study and make comparison with healthier populations with HIV infection more difficult.

Frank Lamendola (1994) examined the experiences of nine gay men, five with AIDS and four with HIV infection, to describe the concept of expanding consciousness. In coming to terms with living with HIV/AIDS, these men described a changing quality of life. They described feeling good about themselves and more in charge of their lives. They were able to open up to a fuller expression of caring and sharing with others. They felt they took advantage of opportunities more than they had in the past and also described a deepening spirituality. All the men in this study had a history of alienation from their families in the past and had broken away from their families. They then experienced cycles of aloneness and searching which often involved experimentation with alcohol, drugs, and sex. A combination of HIV/AIDS with these cycles led many to a turning point at which time they experienced the changing quality of life described above. This study is useful in that it describes a life history frequently seen in gay men who have been stigmatised and rejected by their families. This strength may 
however be a limitation in that many gay men do not experience that alienation, or if they do, not to the degree described in the case study included in the article.

\section{Conclusion}

This chapter has described the research and findings related to uncertainty and illness published during the last eight years. Studies have focused on women with breast cancer, gynaecological cancer, and rheumatoid arthritis. Uncertainty has also been explored in the field of cardiovascular disease and in parents of children with life-threatening illness.

Uncertainty has been noted to occur in people with HIV/AIDS. However, studies describing this phenomenon have not been reported to a large extent. The responses of individuals with HIV/AIDS to living with a life-threatening illness have been described in terms of selftranscendence and expanding consciousness. This study will hopefully add to the small body of knowledge about uncertainty in HIV infection. 
CHAPTER THREE

\section{METHODS}

\section{Introduction}

This chapter will describe the design of the study, the population and sample, as well as the recruitment of subjects. The setting in which the research took place and obtaining consent to participate will be detailed. Included is also a description of the instrument used, the interview technique and how analysis of data was performed. Finally, validation of the data is discussed.

Subjects and Recruitment Procedure

A convenience sample of twenty four HIV infected individuals in Winnipeg was asked to complete the Mishel Uncertainty in Illness Scale (community form) (Appendix 7). This number of individuals provided a large enough sample to supply a range of scores on the Mishel Uncertainty in Illness Scale. This represents almost $5 \%$ of the known HIV positive tests in the province of Manitoba (Manitoba Health, 1994) and although smaller than the sample size of studies which have used Mishel's scale, the number of subjects is comparable to those studied by Weitz (1989) and Laryea and Gien (1993). Only those with confirmed HIV serostatus in the absence of an AIDS defining diagnosis were asked to participate. Of the total sample, a sub-set of ten individuals was asked to participate in a further interview to explore the consequences of uncertainty in greater depth.

Individuals known personally to the researcher through previous 
professional work in the field were approached (Appendix 2) as well as patients attending the practice of a physician in the community who is an expert in the care and treatment of HIV infection. This physician had indicated his interest in the study and offered to refer individuals to the researcher (Appendix 3). A poster advertising the study was displayed in his waiting room (Appendix 4). A short explanation of the study (Appendix 5) was provided to all suitable patients in his practice and those who were interested called the researcher to set up an appointment at a mutually agreeable time and place. Only one person from this practice indicated an interest in participating in the study.

Both men and women who are infected with HIV were eligible to participate in the study. Subjects were asked to provide the year of their birth and number of years of education for demographic purposes. No other identifying information was included.

The researcher explained the purpose of the study to subjects prior to obtaining consent. Any questions about the subject matter (i.e. uncertainty) were dealt with after the subjects had completed the questionnaire so as to minimize the social desiribilty effect and to avoid learning effect through coaching and learning.

The subjects were given the opportunity to obtain results of the completed study from the researcher by completing a tear-off portion of the consent form. 
Consent

Informed consent was obtained from each individual willing to participate in the study (Appendix 6). Consent to participate in a focused interview was obtained in addition to consent to participate in the first phase of the study, that of assessing the extent to which uncertainty exists in the lives of people with HIV infection.

Participation in the study by those individuals referred from the practice of the community physician did not affect their care in any way as the physician had no knowledge of which of his patients participated in the study. Individuals could withdraw from the study at any stage and could refuse to answer any question they wished. During the focused interviews, the participant could request that the tape recorder be switched off during the interview.

All participants in the study were assured that information given to the researcher would be kept strictly confidential and that completed questionnaires would not contain any identifying information. Any reference to names were deleted from the transcripts of the interviews.

The Setting

The questionnaires were administered, and the interviews conducted, at a place convenient for both researcher and subjects. The confidential nature of the information elicited was taken into consideration in choosing the location for meeting. All but one of the participants chose to be interviewed in their home. One participant elected to meet the researcher at a McDonalds restaurant where the 
questionnaire was completed.

Every attempt was made to ensure that the subjects felt safe to divulge information. The home setting allowed the participants to be comfortable and to feel relaxed.

The Instrument

The Mishel Uncertainty in Illness Scale - Community Form (MUIS -C) was used to quantify the prevalence of uncertainty in this sample of individuals living with HIV infection (Appendix 7). This 23 item Likert-format scale is intended for use with people who are not hospitalised to quantify uncertainty according to Mishel's theory of Uncertainty in Illness (1988) .

Reliabilities for this scale as measured by Cronbach's alpha coefficient range from 0.75 to 0.90 (Mishel, 1990b). This scale has been used in studies of epilepsy, coronary artery bypass, lupus, post myocardial infarction, multiple sclerosis and cancer (Mishel, 1990b). Normative data have been compiled for results from these six studies with 396 subjects in total and uncertainty scores in these studies range from 23 to 115 with a median score of 69 . The mean uncertainty scores of 41 to 63 in the six studies fall below the median score.

\section{Interviews}

A sub-set of ten individuals was asked to participate in focused interviews to explore the consequences of uncertainty in their lives. A purposive theoretical sampling technique was used to recruit participants for the interviews. Scores obtained by subjects on the 
MUIS-C were used as a basis for sample selection. Individuals who scored in the high and low ranges of the total sample were asked to participate in the interviews. This was accomplished by examining the scores of the 24 individuals who completed the questionnaires and asking five of those who scored in the upper and lower range of all the scores. All ten of those who were asked to participate agreed to do so.

Interviews followed the format of the focused interview (Merton, Fiske, \& Kendall, 1956). This format allows for range, specificity, depth and personal context to be included in the responses to selected questions. The researcher prepared a list of questions to be answered (Appendix 8 - Interview Guide). However, subjects were encouraged to include any thoughts, feelings or experiences they wished to during the course of the interview. All interviews were recorded and transcribed to print.

Allowance was made for referral of any problems that, in the opinion of the researcher, required further nursing, medical or counselling interventions. This was explained to the participants and except for some questions about avoiding people with colds and flu, no concerns were raised.

\section{Confidentiality}

Confidentiality is an issue of great importance to many individuals with HIV infection who fear negative consequences should their health status become known to others without their express permission. Sensitivity to this has formed part of the professional 
culture in which the researcher has worked for the last four years and all necessary steps have been taken to ensure that confidentiality is maintained.

While it was necessary for the researcher to be able to identify individuals for in-depth interviews from completed questionnaires, each questionnaire was coded and a master list kept of codes and participant names. This master list has been kept under lock and key for the duration of the study and will ne kept secure for a period of seven to ten years.

The focused interviews were recorded. These recordings were transcribed by a professional typist who is knowledgeable about the need for confidentiality. Any mention of client names were deleted from the printed transcripts. Completed questionnaires and the tapes and transcripts of the interviews will be kept in a secure place for the recommended seven to ten year period.

\section{Ethical Considerations}

To protect the anonymity of the participants, names and identifying information in the transcripts have been changed in the narratives presented in Chapter Four. This has been carried into the thematic analysis portion of the findings.

Participants were adviced of this prior to the interviews taking place. many of the participants stated that they were willing to have their real names used however all names have been changed. To further protect their identity, descriptions of occupation and living conditions 
have also been altered.

\section{Analysis of data}

Non-parametric statistical analysis techniques were used due to the small size of the sample. The data obtained from the MUIS - C was analysed for mean score as well as range and median score. Individual scores were compared to the range of normative data for this instrument. According to this scale, uncertainty is measured along a continuum from a low score of 23 to a high score of 115 .

As only two of the respondents were women, it was not possible to compare male and female respondents using a Chi- square test. This is probably due to the small number of HIV infected women in the province of Manitoba and also due to social factors, such as women fearing loss of anonymity and being reluctant to participate in studies. The effect of education and age on uncertainty was measured using Spearman-Brown and Chi square correlations. In addition, any relationship between years since diagnosis and score on the MUIS-C for those ten individuals who participated in the interviews was sought.

Transcripts of the interviews were reviewed to identify themes or categories of responses that are similar. Words, phrases, and themes were written in the margins of the transcripts. The method described by Burnard (1991) was used as a guide for the analysis. This method combines elements of grounded theory and content analysis and involves a fourteen stage process to produce a detailed and systematic report of themes and issues contained in the interviews. In the first 
stage, notes are made after each interview describing the content of the interview. In stage two, transcripts are read through and general themes are noted. The transcripts are read again in stage three and multiple headings are noted in the margins. In stage four, headings are grouped together under higher order categories. Stage five involves reviewing the list of headings and categories to identify repititions which are then deleted. Stage six requires a review of the categories by a colleague and if there is agreement, the process is continued in stage seven with a review of the transcripts and the headings and categories. In stage eight, the transcripts are coded according to the headings and categories, usually by highlighting the transcripts with different coloured highlighters. The coded transcripts are cut up and grouped together in stage nine. These cut up sections are glued to large sheets of paper in stage ten. Stage eleven involves asking participants to check the appropriateness of the categories. Stages twelve and thirteen involve filing the sections together for the written analysis and beginning the writing process. The final step, stage fourteen, related to how the analysis is written and whether it is related to the literature in the same chapter as the findings or whether the analysis is written up in a separate chapter.

In this study, three of the respondents were asked to validate their statements and the appropriateness of the category system. No corrections were necessary. Five of the transcripts were reviewed by a member of the thesis committee to confirm themes. 
Validation of the Data

According to Sandelowski (1986), qualitative research "emphasizes the meaningfulness of the research product rather than control of the process". However, some measure of the rigor of this type of research is possible and this study will be examined using the criteria of credibility, fittingness, auditability, and confirmability (Guba \& Lincoln, 1981).

Credibility refers to the "faithful descriptions or interpretations of a human experience that the people having that experience would immediately recognize it from those descriptions or interpretations as their own" (Sandelowski, 1986). To this end, the researcher in this study presented the findings (themes and strategies) to three of the ten respondents and asked for validation of these findings. All three participants agreed that the themes and strategies were appropriate and did reflect their experience.

Fittingness is a term used by Guba and Lincoln (1981) to describe the "fit" of research findings into contexts separate from the study and when others who read the findings find them meaningful in terms of their own experiences (Guba \& Lincoln, 1981). The fittingness of this study has been tested by discussing the findings with health care professionals and people who have worked with this population who agree that the themes and strategies do describe the experiences of people with HIV infection.

The third criterion suggested by Guba and Lincoln (1981) to test 
the rigor of qualtitative research is that of auditability. The findings are said to be auditable when others can follow the process used by the researcher to arrive at the findings. The transcripts, memos, open coding, headings, categories, and final themes and strategies have been examined by a member of the thesis committee of this study. She agreed that the conclusions reached are appropriate.

Guba and Lincoln's (1981) final criterion for rigor is that of confirmability and this is said to occur when auditability, credibility, and fittingness are achieved. The results of this study meet this criterion. While the sample size of this study is small, this should not detract from the validity of the findings. The findings reflect the life experiences of the participants and describe both typical and atypical examples of these experiences (Sandelowski, 1986).

To further enhance validity, a personal journal was kept to describe the emic perspective of undertaking this research. This researcher has worked with people with HIV infection and ADDS for a number of years and this clinical experience has formed the background for this research. Careful attention was paid to personal feelings and thoughts in the process of conducting the research which might enhance the researcher's understanding of the phenomenon being studied and thus influence the outcome of the analysis. A section on reflexivity and reflection is included in Chapter Five. 


\section{Conclusion}

From personal clinical experience over the past six years and from the literature, it appears that those living with HIV infection face uncertainty on a variety of levels. However, this does not appear to have been measured in any studies in the past.

The objective of this study was to determine the level of uncertainty in a sample of individuals with HIV infection and to further explore the consequences of this uncertainty through focused interviews. This process identified areas for further research as well as provided descriptions enriching the existing nursing knowledge base. 
CHAPTER FOUR

\section{NARRATIVES}

\section{Introduction}

Descriptive narratives allow for the stories of individuals to be told and enrich the researcher's understanding of the phenomenon under study. Insight is gained into how the individual respondent understands and visualises his or her experience (Sandelowski, 1991). The stories of the ten individuals interviewed in this research project need to be told. They stand as a testament to the lives of these people and attempt to keep the individual experiences of those that live with HIV infection unique and separate from the cold statistics of disease state and mortality.

All ten of the respondents interviewed are well known to the researcher. Over the past five years interactions and sharing of life stories has taken place at regular intervals. These recollections form a background to the conversations recorded for the purposes of this research.

\section{$\operatorname{Tim}$}

Tim is 30 years old; a tall man who seems comfortable with his height and broad shoulders. When he was 15 years old he told his family he was gay; his father's response was extremely negative and he left home. He has visited his family only once since then when he went home for Christmas two years ago. He has, however maintained contact with his mother over the years. 
Tim was diagnosed HIV positive early in 1992. The results came as a shock as he had tested negative a number of times in the past.

I've always gone to school and church talking about AIDS and some of the ways people can protect themselves against the infection and for me to have the shoe on the other foot, so to speak, it took a lot out of me. (Interview 4; p.2)

These speaking engagements are very important to him; in some way he thought that by educating others he was protecting himself from HIV infection. He admits that he knows where and by whom he was infected but attaches no blame and does not dwell on the subject. Now when he speaks to audiences he does not tell them he is HIV positive.

I only give them the information they need to know and that's all they need to know. (Interview 4; p.22)

Telling his family about the diagnosis was not easy. He had fears of abandonment initially but they have now come to terms with it although some of his nieces and nephews do not talk to him.

One time my father answered the phone. He yelled, “Oh it's the fag of the family" and then he turned around and said "Oh it's a wonder he hasn't got AIDS yet" and then I said "Well, I got one up on you, I'm HIV positive" and hung up the phone. And then I realised my mom picked up the extension. (interview $4 ;$ p. 12)

His mother called him back and they cried together and she reaffirmed her love for him. He sent her a book about HIV to read and she continually asks him about his health and the care he takes of himself. He feels that they are now closer than ever before. 
Most of his friends know about the HIV infection and he is open in the gay community about it. However he has been very lonely in the years since being diagnosed and at times very depressed. Recently he met someone and talking about this relationship causes a broad grin to light up his face.

"Before I met my partner I was alone. I was tired of being alone, coming home alone, and things have changed considerable." (Interview 4; p. 4)

Tim's view of the future has changed since diagnosis. He is unable to work due to the physical limitations of fatigue and living on Social Assistance is difficult. He feels that much has been taken away from him.

I've always been quite active and I felt like, since I've been diagnosed, it's all been taken away from me and I have to readjust my life again so to speak, to make things easier. (interview 4 ; p. 7)

Tim has had some medical problems which are unrelated to HIV infection. There are days when he experiences severe headaches and he is scared of needles so he delays going to the physician. He is knowledgeable about his condition and is proud of the role he plays in educating others.He accesses information from the library and his health care providers and, after an initial period of shock, found that his need for information continued to grow.

I have mentioned to my doctor that I don't want to be treated like a child. I want to know everything up front. All the and, ifs, or buts, or whatevers, that is involved. (Interview 4; p. 15) 
HIV infection has affected Tim's life in many ways. It has brought him closer to his mother but it has taken away his job and forced him to live on a limited income. He states that he has grown as a result and appreciates life a lot more than he used to.

It was a real hit in the face. It can happen to anybody. It doesn't matter who you are. (Interview 4; p. 21)

His summation of how HIV has impacted his life is spoken in the words of one who is used to educating the general public about the dangers of distancing oneself from the HIV epidemic. "It can happen to anybody. It doesn't matter who you are.”

Stan

Stan lives with his partner in an apartment overlooking a park. He spends a lot of time alone while his partner is at work and music plays continually in the background. Stan is a small man with delicate features and movements. He was diagnosed six years ago and remains healthy. He had tested negative for HIV a number of times but seems unsurprised that the fifth test was positive.

I mean I can't say and I don't really know who I got it from or how I got it but I know at some point in time something must have happened when I got the results I wasn't really upset or anything... it just surprised me that it didn't happen sooner. (Interview 5; p. 1)

Stan describes the events around receiving the test results in relation to how others involved responded. He describes how the 
physician was crying and how a counsellor was called and together he and the counsellor calmed the physician. Then his partner at the time was called and he and the counsellor together told his partner.

It seems as if this distancing of self from the reality of having HIV is a way for Stan to cope. Many of his comments about living with HIV are described in terms of how others deal with it.

I've heard a lot of people getting upset about their $\mathrm{T} 4 \mathrm{~s}$ and saying "Oh, I got a bad T4 count. (Interview 5; p. 3)

I sit there and look at other people, other HIV positive people, there are certain people that, their disease is their life and if they weren't HIV positive or didn't have AIDS. there wouldn't be anything else going on in their life and, God forbid, that would happen to me. (Interview 5; p. 8)

Stan has been unemployed for 16 months. He was diagnosed with a musculoskeletal problem and the doctor suggested that he give up work he states that his health has improved and that he has gained weight since then. Many of his friends are HIV positive and he attends a support group regularly. He has concerns about certain aspects of his medical care. He is frustrated by the lack of government funding for AIDS-related programs and he is not completely happy with his present physician. However he is unwilling to transfer his care elsewhere.

I don't want to (transfer care) because I want to do what I want to do and if something is right and I know what Im doing is right, I'll make sure that things get done the way I want and if I know something is wrong. I will try my best to fix it. And to that extent I'm classified as a shit disturber from the facility and the doctor's point of view and I will force the issue on the doctor. (Interview $5 ; p .16$ ) 
Stan feels that he is very informed about his disease and any progress being made in research. He subscribes to a number of treatment bulletins and describes his participation in a research study. Once again he distances himself by detailing how his involvement with the researchers is focussed on others with HIV.

So they can tell the nurses or the doctors that if a patient comes in with these symptoms that they qualify for this study and then they can go. (Interview 5; p. 19)

Stan's biological family found out about his HIV status when he was quoted in the newspaper on an issue relating to HIV. He thinks they may have suspected he was gay but this is not something they have ever discussed.

If they ask me outright I will answer the question honestly, but if they don't ask I'm not going to volunteer. (Interview $5 ;$ p. 11)

His partner is supportive and understanding of what he goes through on a daily basis in living with this disease. However, the future is more uncertain.

At one point he (partner) said, "If you ever get to the point where you're sick and you are going downhill, I won't be able to handle seeing you like that'. So at that point I (Stan) will leave and end the relationship because of my medical problems and that kind of bothers me. It's just, if you care that much about a person, you have to be able to see them through the good parts and the bad parts but psychologically he won't be able to handle it. It's just the type of person he is. (Interview 5; p. 14) 
Stan's partner may very well do what Stan fears; he was involved previously with someone who was HIV infected and they are now not even on speaking terms. But Stan rationalises that worrying now about him leaving is futile and they continue their relationship with unresolved issues.

Stan regards being infected with HIV as a "wake-up" call. He believes he has changed his outlook on life because of it and is a better person for it. Once again he distances himself when he speaks of how people respond to those with HIV infection.

I guess my point is you can't judge people. I mean you have to take the person as a person for who they are and what they are if you can be a friend to the person as opposed to the disease or their sexuality, it makes a difference.

(Interview 5; p. 26)

Despite his involvement in a support group and the physical presence of his partner in their home, Stan presents an image of a lonely man. He speaks of HIV infection as it affects others and faces an uncertain future with one who may leave just when he is needed the most.

\section{Ron}

Ron is a handsome man with deep laugh lines running down the sides of his mouth. He has battled depression most of his adult life and has had a number of hospital admissions. It was during the last admission that he was tested for HIV. He feels he was pressured into having the test; he had tested negative some years before that and 
believes the doctors wanted to test him because he was gay. The results were given to him by his own physician two weeks after he was discharged. He has forgotten many of the details of how he felt at the time. Much has happened since then.

Ron has a high $\mathrm{T} 4$ count and remains healthy despite poor eating habits, smoking, and drinking large amounts of coffee each day. He lives with his partner who is also HIV infected. The two men do not talk about it much. Ron avoids watching television programs about HIV because he feels it upsets his partner who he thinks is in denial about his HIV disease.

For Ron, HIV has been the impetus for great spiritual growth. He comes from a very religious family and although their Christian beliefs are not the same as his, the thread of a belief system runs through his life.

I was a victim all my life. I was, when most people are, especially what you say from the Christian upbringing, you're taught to be a victim of life and that it is perfect to be a martyr and I realised...it gave me a wake-up call not to be a victim. (Interview $6 ;$ p. 19)

Ron has told his family about his HIV status and they are accepting of him although it was difficult for them to deal with his homosexuality. 
We basically don't talk about it. It was said, it's out in the open. But it's very seldom brought up and that's the best. I mean, it's brought up when it's appropriate, that yes, I am going to die, yes, but you're also going to die. I might just go a little quicker, that's all. And especially with parents, no parent wants to think their child will die before them and so that's a little harder. But we've worked, as best we can on the issue. (Interview $6 ;$ p. 12)

Ron spends time each day in quiet meditation and listening to

New Age music. He works as a nurse and finds time each day to nurture his spiritual development.

Some people would think it's a waste of time but I find that it is more helpful in the ways because you actually don't waste time. You recollect your thoughts and look at your goals where you're going and redefine yourself again. (Interview 6; p. 10)

Ron has thought a great deal about death and the importance of living life to the full. He plans to "do it as peacefully as I can"although he hopes it will not be soon. Life is important to him and even more so, the way we live our lives.

We being a quilt, I would like to call it the rainbow quilt of the human, well I won't even say of creation. And it can be a joyous quilt if you get on with the weaving of it and leaving love behind and expressing love...love combines a lot of things, in other words, heroism, generosity, things like that. If you try to define that into your life and being, instead of a taker, a giver...expanding that into your life whatever tradition you have... you become a weaver. (Interview 6; p. 20) 
Ron has made peace with himself and lives each day, working at his profession and enriching his spiritual life as best he can. He speaks of the importance of love and this is evident in the quick glances he make toward the kitchen where his partner prepares coffee. He is a giving man and in his generosity to others he receives in kind.

\section{Jake}

Jake has been HIV positive for eight years. He went to be tested based on a personal assessment of high risk activities in the past and was not surprised when the test results showed he was indeed HIV positive.

He has integrated this into his life although taking medication four times a day serves as a constant reminder. Taking anti-retroviral medication is fairly new for him. Two years ago his T4 count had dropped to a level where some physicians recommend beginning therapy.

The AZT was a confirmation of that diagnosis (but) I think it probably wouldn't have been much of a shock or a problem if say, I would have had to start taking it right away..but when after six years and then all of a sudden.. (Interview 3; p. 4)

Jake has three adult children and having HIV has made him think about his relationship with them and the time he has missed while they were growing up in Ontario.

Where has all the time gone? It seems like yesterday they were babies and I want to do more things with them and spend more time with them. (Interview 3; p. 7) 
He maintains close contact with his parents but has chosen not to tell them about the HIV. They know that he lives with a male partner but the issue of homosexuality has never been discussed. They live in a small town and Jake is reluctant to cause them any problems.

This attitude is born out in his daily life; few people know about his HIV status and he intends for the situation to remain the same.

I find it harder to disclose your status in a small community because of the stigma that it carries. I've never disclosed my status with any of my employers for that reason or for the reactions they may have, not always positive. (Interview 3; p. 10)

Jake and his partner live a quiet life with a few good friends. Jake feels he is dealing with having HIV and feels no need for a formal support group. He is pragmatic about seeking out information about the disease. He lives life day by day and does things that bring him enjoyment. He avoids stress in the workplace as much as he can and has passed up opportunities for promotion because of the additional pressures involved. He and his partner travel whenever they can and have plans for an extended vacation in South America later this year.

I live life day to day and try to make the best of the time I have now, the travelling and maybe taking life a little easier, treating myself a little better and enjoying things. (Interview $3 ;$ p. 16-17)

Jake's acceptance of his past and it's impact on his future is matter of fact. He recalls the sexual freedoms of the 1970s with some wistfulness. 
I came from a time when, prior to AIDS, it was very good. It was very open. It was lots of fun...I feel sorry for the younger ones who didn't have that. See, like there again I'm saying I've lived that so I don't need it. Why should I feel regret, I at least had that opportunity whereas the younger ones now don't have that opportunity. (Interview 3; p. 16)

Jake looks to the future with pragmatism; he is happy with his life as he has lived it and is prepared for what may yet come. His only regret is that he is far from his children and has missed much of their growing years.

Gail

Gail spends most of her days alone, the air around her grey from the cigarettes she smokes constantly. Her small apartment is tidy with house plants placed on every available surface. On the table sits a medication organiser; the small compartments are filled with tablets and capsules. They look like colourful beads waiting to be strung.

Gail's life has been one of constant struggle. She has lived most of her adult life on the streets of Toronto in search of the alcohol and cocaine that eased the pain of her past.

She was tested while in prison four years ago. She did not know that she had been tested and life has never been the same for her again.

I didn't even know anything about it....I was in jail when I found out and the way the nurse told me was that I have AIDS and I thought I was going to die. (Interview 1; p. 1) 
Having HIV has fundamentally altered her life and the way she sees herself. She has been clean and sober for four years after leaving the streets. She has contact with her family again and is forging bonds with other HIV infected people. However her view of herself is anything but positive.

All my life I was brought up being called dirt and bad and now I really believe it. It's like I feel like Im being punished all over again...Im an adult and I should know the difference but I can't help feeling like that. (Interview 1; p. 6)

She feels a great deal of shame and believes that her family avoid touching her. She also thinks that they know more about her medical condition than she does and that they are not telling her something. She interprets loving gestures from them as a sure sign that she is going to die soon.

It wouldn't be too bad if they told me to my face, like "I'm scared 'cause I don't know what's going to happen, that's why I won't kiss you or hug you". But instead they go behind my back and then it gets to me and it hurts. (Interview 3; p. 7)

She's (her mother) got to have seen something or something is terribly wrong with me. Nobody's telling me so I think she's seen the light. (Interview 3; p. 22)

Gail spends time thinking about past hurts and failures. After many years of drug and alcohol abuse she is raw from the emotion of it all. She no longer blunts her feelings with chemicals and many of the feelings are new to her. 
Im fighting this sober and clean, like not doing no drugs or...and I'm sober. (Interview 1; p. 9)

Her family visits periodically and the visits are not always easy for her. She is suspicious of their motives and finds it hard to take pleasure in their company. Perhaps the family's history of abuse and pain contaminates their interactions even now.

Like I think I disappoint them because I'm not dead yet. You know, like when I first came back I was skin and bone and they were there to see me and everything you know. My brother came in. That's shocking. He came to see me but then I think I... As soon as I started getting better they stop coming around. So that's what I mean by I think I disappointed them that I didn't die. (Interview 1; [. 13)

She has isolated herself from people she knew before and avoids her neighbours for fear that they will discover her condition. She attends a support group and relies on members of the group for information about the disease. However, she is not always happy with what she hears.

I'm afraid because what little bit I've found out more has really scared me so I didn't think I really want to know any more. If I did want to know any more it would be to educate my family. (Interview 1; p. 19)

For Gail, living daily with HIV is yet another battle to be faced. She is scared of the future and finds no comfort in the present. She is frightened of what people say and think about her. 
I don't want to say that but part of me doesn't want to fight no more. And that scares me. 'Cause I am a fighter, I always was. I was a survivor. (Interview $1 ;$ p. 14)

Gail has so much pain in her past and present that thinking of the future is almost impossible for her. There are enough uncertainties in her daily life that what lies ahead is incomprehensible to her. In the past she has always been an outsider both within her family and society. HIV in her mind, has made that an intractable position.

Bill

Bill is a man of secrets. He was married for five years and three years ago the marriage ended. For years he has kept his bisexuality secret, at one time he did not admit it even to himself. He went for HIV testing in response to his ex-wife having had sex outside of the marriage. He was shocked when his test came back positive; he does not discuss any high risk activities he may have participated in.

For many years he has suffered from inflammatory bowel disease and is used to medical appointments and surgery. In the months following the diagnosis of HIV infection Bill found it very difficult to cope and stopped work. He has recently come to realise that some of the early signs of HIV infection coupled with the sequelae of inflammatory bowel disease make employment almost impossible for him. This has had a major impact on him. 
I feel really lousy and Im just starting to learn that the last couple of months. Terribly painful. In the back of my mind it (employment) was always something I would get back to or would work into something else but that I would find some way to measure myself successful and that hasn't happened yet. (Interview 9; p. 6)

Bill experiences fatigue and depression and is on a number of different medications. It is sometimes difficult for him to differentiate between the side effects of medications and symptoms. He attends a support group and finds himself cataloguing the symptoms and complications of others in the group.

A piece of me is glad it's not me. I also keep thinking that I'm overdue or...I have a bit of a martyr attitude about me so if I'm not careful I can very easily play the sick role. (Interview 9; p. 8)

He told his parents of his diagnosis soon after he found out. Their response has been overwhelmingly positive and he derives great emotional support from them. He has had a number of relationships in the three years since his diagnosis. He seems to become involved with women who want to protect him and are willing to nurse him and be there until the end of his life. This causes problems.

It's okay for me to say "I figure I've got four or five years left". When you hear someone else say, "Well, we've only got four or five years left" that really hurts. (Interview 9; p. 16) 
Bill has a five year old daughter from his marriage and he sees her regularly. He had begun to keep a journal which she will one day read. It is his attempt to leave her something that will enable her to get to know him after he is gone. The act of writing in the journal is an exercise in introspection for Bill.

'Cause there's a sense of, you become really mortal with this you know. Otherwise you just assume your kids will find out about you, you'll be there and all of a sudden the disease is telling you that you may not be there. And I'd like her to know me and if she can't know me by being with me then perhaps through the pages. (Interview 9; p. 14)

Despite personal losses because of his illness, Bill states that he has grown and matured as a result of having HIV. He maintains hope but his vision and aspirations are restricted.

I don't believe I am going to beat it. I joked once about being the first guy to beat HIV but the last little while the way it has caught up with me and how I've come to my physician with symptoms of fatigue and leg weakness problems and things like that. And she said, "Well, that's just something you're going to have to accept". And I was fighting it the whole time. That happened in spite of my working out, in spite of my best efforts and it's too powerful for me, you know. (Interview 9; p. 24)

He has faced HIV infection with the intention of "doing it right". He is informed about the disease, he has joined a support group, he recognises his mortality, he is willing to accept the signs and occurrence of disease progression.

There is a sense of resignation about Bill. However he seems to be 
searching for something that is just out of reach. There are times when he is very lonely and he seeks out new relationships. But he often ends the relationship when the woman gets too close or seems to stifle his hope. Perhaps his greatest secret is that despite appearances, he really has not accepted that he is going to die.

\section{Gregory}

The walls of Gregory's apartment are covered with large coloured photographs. The same man appears in many of the photographs; in some he appears healthy while in others the insidious decline of HIV wasting syndrome is all too apparent. This is Wayne, Gregory's partner of four years who died two years ago. Gregory himself is a large man with a ready laugh and an appreciation for fine food.

Relationships are important to Gregory. His life is filled with many different people and his generosity of time and spirit has been rewarded by a large group of friends who care for him in turn. Alcohol has played an important part in his past but three years ago he stopped drinking and many of his friendships now are focussed within his AA group.

He tested for HIV after careful consideration of his past risk behaviours and a degree of suspicion that he might be infected. The test was positive.

I don't think I was shocked. I handled it the same way I handled any other crisis. I drank, (Interview 8; p. 2) 
He shared the news with friends and family who were supportive.

It took some time for him to come to terms with the knowledge.

There was a period when I was over the map and felt way out in the dark and every time I cut myself I'd look at that and go, "Oh God, here comes that infected blood" and stuff like that. (Interview 8; p. 3)

Eight years have passed since then. Gregory now feels he can contribute to others and achieves this by political activism and involvement in fund raising activities for AIDS-related causes. He has made strides in improving his lifestyle. He no longer smokes and is careful about what he eats. Attendance at AA meetings and the philosophy of a twelve step program have changed his outlook.

I want to make sure that today is good and want to do a little bit of preparation to avoid major disasters tomorrow and that's all I worry about. (Interview 8; p. 10)

He enjoys his work as a janitor in a high school but is clear that as soon as he experiences any deterioration in his condition he will quit.

If I start to get sick I will find a way to get myself retired 'cause I want to travel. You know I got a lot of friends I have to go and hug. (Interview 8; p. 9)

On a recent visit to an HIV infected friend in British Columbia he learned of a variety of treatment bulletins that are published in the United States. He has begun to subscribe to these and makes a point of passing on information to others. This is part of his contribution to his community. 
He opened up a whole new world for me. He showed me the stuff that he was doing... It's dinner table talk for (HIV) positive people and he had this vast knowledge...That really inspired me so I got the name and addresses of all the places where he got the information and signed up. (Interview 8; p. 17-18)

Gregory has not had any symptoms related to HIV. He has elevated cholesterol levels and some liver damage from his years of drinking. HIV is part of his daily life in that he has memories of friends lost and concerns about ones that are ill.

Some aspect of it (HIV) goes through my mind but I don't think it's so much from a real concern about that. Tve grown somewhat complacent with my longevity and that's part of it but the other part is I'm involved with so many people who are HIV positive and, as you can see by looking around my place, most of the pictures are people that I've lost...You know HIV is a topic for me every day. But I don't see that as a negative thing. (Interview 8; p. 4)

He told his elderly mother soon after he was diagnosed and was recently interviewed on television. There is no room for secrets or deception in his life. He describes living without secrets as "freeing".

Gregory has not seen any decline in his T4 count in the eight years since diagnosis. He is aware of the link between stress and immune function and makes sure he has a T4 count whenever he experiences a stressful period in his life.

Gregory sees his HIV infection as being a pivotal event in his life. It has helped him establish priorities. He has seen many friends die and is watching still more grow thinner and weaker yet he is filled with hope. 
A man who lives with enthusiasm and gives of himself with ease, he embraces living with HIV as a challenge.

David

David's diagnosis of HIV infection came as a shock to him. A routine insurance medical found antibodies to $\mathrm{HIV}$ in his urine. He was told the results by his physician three years ago. He was devastated by the news.

I thought, “This is the end of my life" right. "I'm going to be gone in months. (Interview 7; p. 2)

It took him almost twelve months to accept the diagnosis however he functions largely in a state of denial.

At first I was trying to block it out of my mind, like after that year of whatever, after I'd come to accept it...It's sort of like in the back of my mind and I wouldn't really think about it that much but once in a while I'm starting to think about it a little more. It seems like every time I take my AZT I think about it. It reminds me of it and I find that if I'm kept busy it doesn't... when I'm working I don't think of it at all. (Interview 7; p. 3)

Depression lurks in the background of David's life. He is employed as a seasonal worker with the city and finds the winter months of lay-off very hard. His partner has a demanding job and is frequently out of the house from early in the morning until late at night. He is supportive of David but often David withdraws, preferring to suppress his feelings rather than discuss them.

He sees his physician every three months and places much 
importance on the results of his T4 count. He tends to ignore any symptoms that occur between regular visits and will often not tell the physician about them.

Maybe I'm too scared to bring it up because maybe it is something that I should be worried about and I don't want to worry about it. (Interview 7; p. 5)

David feels ashamed of his HIV status. He denies getting HIV through unsafe sexual activity but feels that anyone who knows he has HIV will assume it was through unsafe sex.

You hear all these things about how people get AIDS and it's just the way I believe I contracted it because it wasn't through sex so...I just sort of put myself in that same category as like I'm terrified to tell anybody about it because people think, "Oh you got it through unsafe sex, don't you know any better" and that's what scares me a lot. That you're labelled with this disease. (Interview 7;p. 6)

His family knows he is gay and he has told only a few close friends. To the outside world he projects an image of a young man living with a friend. The reality is much different. He and his partner have spoken about the risks and benefits of telling their families about David having HIV. They would both gain support from their families but David is reluctant to disclose.

What I think I want to do is maybe wait until there comes a time that I am sick and then we'll tell them because I don't want to put any extra pressure on either family. To me, I think of it as what they don't know won't hurt them like if they don't know about it they won't be worrying about me all the time. (Interview 7; p. 9) 
David feels that time is passing very quickly for him. He feels pressure to do things like travel while he is well. He has very little faith in a future.

Like I want to go away for the weekend and he'll (his partner) say, "Well, I'm too busy with work". And I'll say, "Well, let's do it because what if $\mathrm{Im}$ not able to next weekend or whatever, let's do it now". (Interview 7; p. 8)

Having HIV has changed every aspect of his life. He has put aside any career aspirations, fearing that he may not be well enough to succeed and that if employers find out, he will lose everything. He keeps a large part of his life secret from his family who would be a source of great support to him. Many of his friends do not know that he is gay and this secrecy is a source of friction between his partner and himself. Reading about HIV causes him anxiety but he waits for a miracle drug, hoping that medical science will provide him with a future. He remains passive, counting the days as they pass, wondering when his allotted number will run out.

\section{Robert}

Robert is a confident man who is at ease in any situation. He runs a very successful film production company that employs 30 people in his home town as well as four on the West coast.

He was diagnosed two and a half years ago when he was tested for HIV as part of an insurance medical. He had avoided testing before because he thought that if he tested positive, there was nothing to be 
done.

The reality of having HIV is different from what he expected. He finds he is taking less for granted now and that he has changed. He is happy with these changes.

You change and I think anybody, everybody who gets the news has to change in some way or other...'cause it is like a major shock. (Interview $2 ;$ p. 7)

He sees changes in himself in the way he conducts himself in his professional life. He is more understanding of others but at the same time less likely to allow others to think they can lie to him or cheat in some way. He describes how he hired a young man who told him that he had cancer as a teenager.

Three or four years ago I would have like, “Hey, I'm not gonna hire this guy...what if he gets cancer again? And Ive spent all the time and effort training him and he's gonna die on me". I hired him and he's done very well for our company and he has problems with his health sometimes, but I mean, you have to work around that. (Interview 2; p. 23)

He gives more money to charity now and treats people more kindly. He laughs when he describes how others react to this new gentler Robert. He sees how he has changed when he looks at how others behave.

I look at them and I think, “Jeez, you're so bloody mean"but I would have been the same way, you know, like three or four years ago...I definitely prefer the me now. (Interview 2; p. 24) 
Whereas before he was diagnosed he avoided anything to do with HIV, now he scours medical journals and text books for new information. He finds very few changes from year to year but feels that this search for information is empowering.

He travels to larger cities on a regular basis and uses those opportunities to listen to what other people with HIV are doing to maintain their health and avoid complications. He takes vitamins daily and has started eating more fresh vegetables.

He told his friends immediately when he was diagnosed but is careful to keep this information in the close circle.

The reason I wanted to keep it in such a tight circle too is I thought, and I still think, that there would be abandonment in the business world. You know, I think that if people knew, if I would be open about it to business colleagues, I think that there would have been a lot of damage done. (Interview 2; p. 13)

He has told one of his sisters but has not told his other siblings. He is one of nine children and he believes they would be constantly calling him to check on him. He has not told his parents who are elderly.

His business is very important to him and he derives a great deal of pride in his personal achievements and the success of the company. He has a partner in the company and knows that should something happen to him, the business would continue. 
I guess for somebody like me who has a business and has a lot of people that are depending on me, Ive got to think about it in terms of what is going to happen to this business if I should die from this illness. Who's going to run it and all of those things. You know I have to look at it that way because I can't think Im going to be making it through this $100 \%$. I mean the possibility is there that two or four years you know.. I can just look at the statistics that I've got to think of things in terms of...if something does happen, how is this business going to carry forward? (Interview 2; p. 7)

Money has always been important to Robert, both as a measure of his success and as incentive to work harder. His long term goals have changed. He no longer thinks of becoming a millionaire at 55 years of age but rather uses his money to travel now and enjoy himself. He is firm in his belief that he must have money put aside for when he becomes ill.

I want to be very prepared financially because, let's face it, money and medication and the things to bring comfort only happen with resources unfortunately, but I want to make sure I'm one of them that has them. (Interview 2; p. 17)

Having HIV has had a profound effect on Robert's life. He manages to balance his daily life with hard work and extensive travel which he enjoys. He has learned the value of personal change and doing things differently. He sees the future realistically but does not allow that vision to rob him of happiness in the present. 
Gordon

Gordon is a quiet man who describes himself as a loner. He lives with his partner and their two dogs on a tree lined street. His daily life revolves around the dogs; he takes them for walks and talks to them constantly. His partner works and Gordon is responsible for most of the housework and the cooking. He takes pride in their home and his ability to provide healthy meals on a restricted budget. He is unable to work due to a back injury.

He tested positive seven years ago. This was an enormous shock to him and his response was to move from the city where he lived to a small town in the interior of British Columbia.

Gordon has severe coronary artery disease and this has more of an impact on his daily life than the HIV. He takes many different medications each day and the anti-retroviral tablets are just some of the many different tablets and capsules.

He lives very much in the present and avoids dwelling on what might have been. Work was very important to him and losing the ability to work has had a major impact on his life.

I know that my days are numbered you know. As soon as I couldn't work any more, that ended my future right there. (interview 19; p. 5)

Living on a fixed income restricts how he lives and what he can do. Holidays are virtually impossible for him to afford. He uses his car as little as possible because, if it breaks down, he may not have the money 
to fix it. He is talented at carpentry and has made changes to the house of which he is justifiably proud.

He has told his family about the HIV. His mother was supportive but some of the other members had a more negative response. He describes how one of his nephews avoided touching him at a recent family get together.

His wife said, "Don't touch him (Gordon). If you touch him you don't touch me". It makes you kind of feel shitty you know. You think, "I'd just like to grab a hold of him and just give him a big hug like I did all my nephews, all my nieces". (Interview 10; p. 8)

He keeps most of his feelings inside and wonders if perhaps this is a contributing factor to his cardiac condition. He does not attend a support group, partly because it is not his way, but also because his partner, who is HIV infected, does.

I don't want to listen to him talking about things maybe that he should be talking to me about.Like how come he's bringing it up here, why didn't he bring that up at home and stuff like that. So you know, it's going to cause friction. (Interview 10; p. 11)

Gordon thinks that his heart condition will probably kill him long before the HIV. He had two major heart attacks three years after he was diagnosed with HIV. He believes that having HIV alters the way medical professionals treat his cardiac condition.

I think that they don't want to do anything where there's going to be a blood situation 'cause they know that I'm having HIV (positive). It's not a question of guessing "Well is he HIV (positive) ?" Like they take precautions with any blood situation now but, with me, like when they did the angiogram, you should have seen the people, they were just 
absolutely covered in plastic. Everywhere. Even across their face. The only thing that wasn't covered were their eyes, you know. And I think as a matter of fact, the doctor even wore glasses. (Interview $10 ;$ p. 16)

Gordon hopes that someone will find an answer to the many questions concerning HIV. While realistic about the severity of his cardiac condition, he longs for a cure for HIV.

I just wish they'd find a bloody answer for it. You know, I'm hoping that I'm going to last long enough for that cure to come through and then I wonder, "Is it going to be reversible, you know ?" Even if it wasn't reversible it would be fine because I could live with the T4 count that I've got (Interview 10; p. 17)

Gordon is a man with many unanswered questions. It seems as if he spends much time each day in silent introspection, mulling over what has been and what is yet to come. All his life he has kept his feelings inside and he continues to do this, unable to share, despite living with a man he loves.

\section{Conclusion}

These narratives describe the journeys of ten individuals from diagnosis with HIV infection until the present time. Each is unique and mirrors the hopes and dreams of the story teller. The following chapter will describe the common themes in the experiences of these people as they journey through life with HIV infection. 


\section{CHAPTER FIVE}

FINDINGS

\section{Introduction}

This chapter includes a description of the analysis of the quantitative data generated from the completion of the Mishel Uncertainty in Ilness Scale (community form). As well, an analysis of the interviews are presented. The thematic analysis yielded an overall phenomenon and five core experiences with associated actions.

\section{Quantitative Data}

Twenty four questionnaires were completed over a one month period. Individuals who were willing to participate in the study were asked to meet with the researcher at a place and time convenient to them. Except for one person, all chose to meet at their home. After signing consent, the questionnaires were completed in an average of 10 minutes.

Of the twenty four participants, only two were women. The participants ranged in age from 23 to 50 and have between 3 and 20 years of education. The scores obtained on the Mishel Uncertainty in Illness Scale (community form) range from a low of 42 to a high of 80 with a mean score of 64 . This range falls within the possible range of 23 to 115. In other studies using this scale, the mean was found to be between 41 and 63 . The mean score of 64 for this study is just marginallyhigher.

Participants were asked to provide their age and the number of 
years of education attained. A Spearman Rank Correlation Cooefficient was performed to investigate any correlation between age and score and years of education and score. The correlation for age and score was -0.2 $(\mathrm{p}=0.3449)$ and the correlation for education was $-0.07(p=0.7465)$.

There is thus no correlation between either age or years of education and the score obtained on the MUIS-C. The correlation for years since diagnosis and score for the ten individuals who were interviewed was -1 $(p=0.1158)$ using a Spearman Rank Correlation test. There is thus no evidence to support any link between amount of uncertainty and length of time since diagnosis.

Bivariate analysis of age and score indicated no significant relationship ( $\left.\mathrm{X}^{2}=8 ; 4 \mathrm{df} ; \mathrm{p}=0.0832\right)$ as did analysis of years of education and score $\left(\mathrm{X}^{2}=0.01 ; \mathrm{df} 2 ; \mathrm{p}=0.9951\right)$.

Participants stated that the questionnaire was easy to use however some of the questions did not apply to people who are not receiving any treatment. In particular, questions $6,11,17,18$, and 20 all pertain to disease related treatments.

Figure 3 shows the range of scores obtained by the respondents. Of the 24 respondents, ten were asked to participate in in-depth interviews. Five of those scoring in both the high and low range of scores agreed to be interviewed. Those with a score greater than 70 were regarded as high scorers. Those with scores below 55 were regarded as low scorers. This was determined by studying the range of scores in Figure 3 and determining the high and low range. 


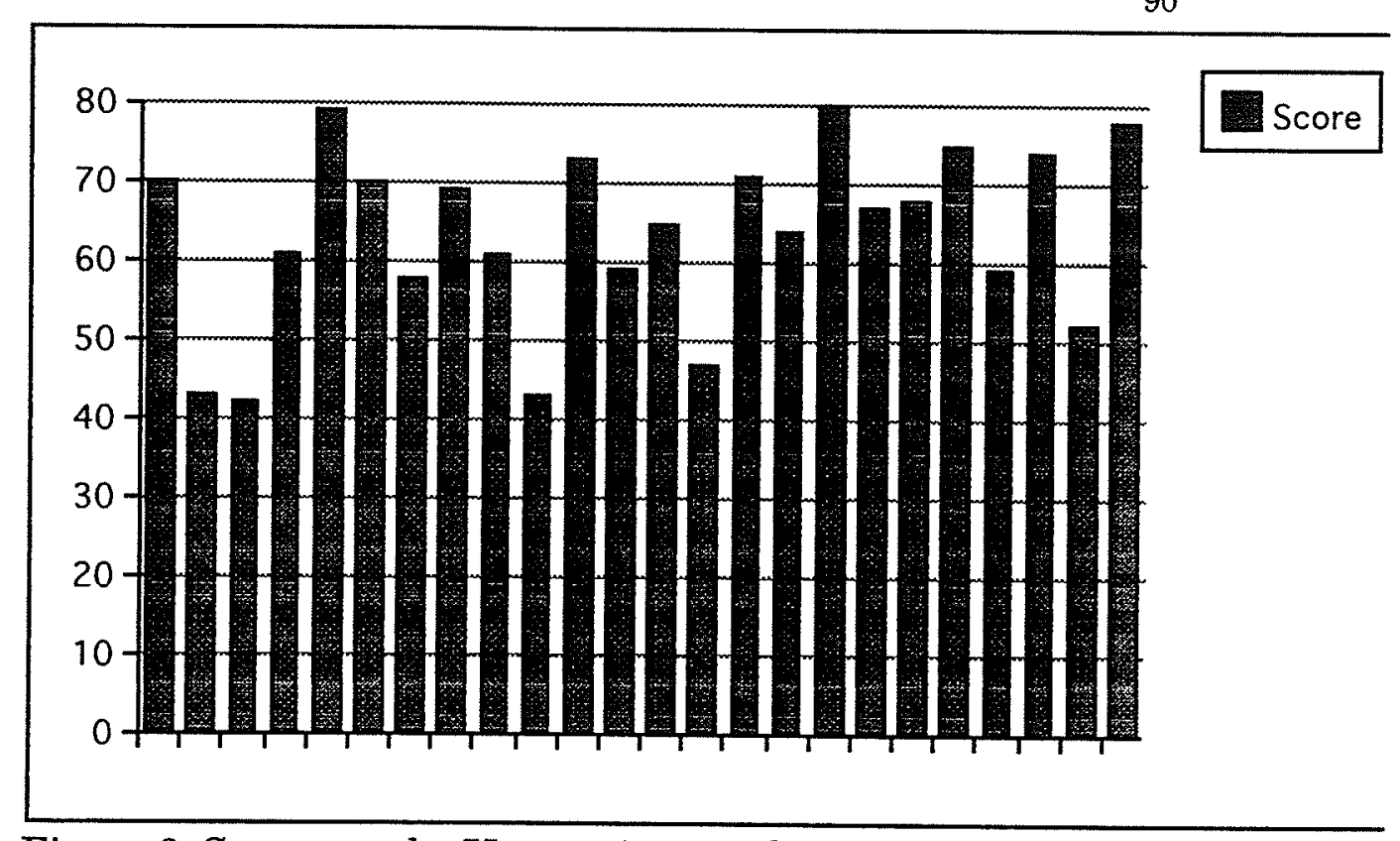

Figure 3. Scores on the Uncertainty in Iness Scale

\section{Qualitative Data}

The ten interviews took place in participants' homes between mid-December 1994 and mid-January 1995. Consent was obtained form the individuals prior to beginning the interview. It was explained that the participant could terminate the interview at any time and could also refuse to answer any question. The interviews lasted from 45 to 75 minutes. They were recorded and transcribed by a professional typist hired by the researcher.

The narratives from these interviews are presented in chapter five. Information from these interviews seems to support Mishel's reconceptualisation of the Uncertainty in Mlness theory. Although this 
sample of ten individuals living with HIV infection is small, it appears that living with a life threatening illness does result in the development of a new perspective on life as Mishel suggests.

A summary of the ten individuals who participated in the interviews is presented below. Names have been changed to protect anonymity.

\begin{tabular}{|c|c|c|c|}
\hline Name & Age & Gender & Soore \\
\hline Tim & 30 & male & high \\
\hline Stan & 38 & male & low \\
\hline Ron & 39 & male & high \\
\hline Jake & 45 & male & low \\
\hline Gail & 41 & female & high \\
\hline Bill & 30 & male & high \\
\hline Greg & 45 & male & low \\
\hline Robert & 35 & male & high \\
\hline David & 27 & male & low \\
\hline Gordon & 50 & male & low \\
\hline
\end{tabular}

Figure 4. Description of participants

The thematic analysis resulted in the description of a phenomenon resulting from living with uncertainty and five core experiences. The phenomenon, Gaining a New Perspective on Life, describes the response to living with uncertainty about HIV infection and the future. The five core experiences illustrate how individuals 
organise their lives within this new perspective. They can be described as Surviving the HIV Diagnosis, Taking Care, Living in the Present, Seeking Support, and Appreciating the Positive.

A number of actions are identified within each core experience. In Surving the HIV Diagnosis the actions include beating the odds, changing expectations, surviving in good health, and beginning to hope. In Taking Care, the actions include embracing spiritual beliefs, monitoring stress, making lifestyle changes, seeking medical advice, avoiding infections, and accessing information. Participants described Living in the Present as changing goals, making every moment count, and viewing the future. Seeking Support involves controlling information, telling family and friends, asking for help, drawing closer to others, and attending a support group. The final core experience, Appreciating the Positive makes use of the actions of enjoying life without regrets, changing personal attitudes, gaining greater understanding, enjoying relationships, contributing to society, and dealing with death.

The phenomenon, core experiences and actions are presented in Figure 5. 
Phenomenon

Gaining a New Perspective
Core experience

Surving the HIV

Diagnosis

Taking Care
Actions

Beating the odds

Changing expectations

Surviving in good health

Beginning to hope

Embracing spiritual beliefs

Monitoring stress

Making lifestyle changes

Seeking medical advice

Avoiding other infections

Accessing information

Living in the Present Changing goals

Making every moment count

Viewing the future

Seeking Support Controlling information

Telling family and friends

Asking for help

Drawing closer to othe

Attending a support group

AppreciatingthePositive Enjoying life without regrets

Changing personal attitudes

Gaining greater understanding

Enjoying relationships

Contributing to society

Dealing with dealth

Figure 5. Themes

Thematic Analysis

Introduction

Analysis of the interviews is intended to yield a systematic description of the themes and issues pertaining to the phenomenon under study. The method used in this study was drawn from a method of analysis suggested by Philip Burnard (1991) and is detailed in Chapter Three. 


\section{Developing a New Perspective}

The perspective one has on life may be described as the way one views life and how one evaluates events and relationships within the life experience. All the participants described being diagnosed as HIV positive as a pivotal event in their lives. This has over time caused a shift in the way they view life. For some, this new perspective on life is positive and they acknowledge that having HIV infection has altered their view of themselves and the world they live in for the better. For others, having HIV has robbed them of a future and while they have developed a new perspective on life, it is one which is bitter-sweet.

For many the diagnosis came as a shock while for others it was expected but remains an event that forever changed the way things are for them. Some individuals had avoided testing before that time despite acknowledged risk factors. For others there was no suspicion or recognition that they had in fact participated in high risk activities. Diagnosis was totally unexpected for them and for many of these individuals, it has taken a long time to integrate having the virus into dailylife.

Over time, all these individuals have begun to see their lives and the world they live in from a new perspective. For a few of the participants, their opinion of themselves has changed and they feel dirty and ashamed. HIV infection carries a stigma and people may feel judged by others. Being diagnosed with HIV infection means that other people have knowledge, real or perceived, of your sexual practices or substance 
use habits. Society views certain sexual practices or injection drug use as deviant and thus participation in either or both of these is also seen as deviant. The majority of participants however, have found living with HIV to be the impetus to begin looking at themselves with honesty and at the world around them with clarity. These individuals may be those who have accepted their sexual orientation and are comfortable with who they are. They are not ashamed and do not perceive the stigma in the same way as those who feel dirty because of the diagnosis.

Relationships are seen as very important and something to be treasured more than possessions and money. Some realise that one cannot change the world; only one's self can be changed and in that way the world is somehow different.

People have seen themselves grow as a result of having this disease and are firm in their belief that this growth would not have occurred without the HIV as impetus. This growth is seen as distinct from maturation.

For some, HIV has seen the beginning of a new phase in which they look after themselves better; one man stopped drinking alcohol, some have begun to pay more attention to the level of stress in their lives, and others have changed their dietary habits. A few of the individuals have become active in the political or educational arena. They have begun to contribute to this new community they belong to, the community of the HIV infected. For those who attend a support group regularly, this sense of community is very real. For others who are 
more isolated, this sense of belonging is less developed but there is an unspoken identity with others who are infected, a feeling of belonging or being somehow different from those who are uninfected. One individual in particular has seen his spiritual life take on new meaning and importance. He is more open to different ideas and experiences and has become much more introspective.

Life after diagnosis with HIV infection is very different from life before even if the individual suspected that he or she might be infected. Developing a new perspective on life seems to take place over time and the individuals interviewed appear to maintain this perspective through five distinct processes. These are illustrated by the following five core experiences.

\section{Surviving the HIV Diagnosis}

For many, being diagnosed with HIV infection seemed to be a death sentence. Preconceived ideas and common beliefs eight or nine years ago led many to avoid testing. When an individual found out he or she was indeed HIV infected, the first thought may have been that he or she would soon be dead and that there was no hope. Over time, people discover that diagnosis is not an immediate death sentence and that they have survived the diagnosis and must now face living with HIV infection.

One woman was tested while in jail; the nurse told her she had AIDS and her immediate response was "I am going to die". She knew virtually nothing about the natural history of HIV infection and the 
response of the prison staff was to call a priest to see her and place her on 24 hour suicide watch.

It's a room that's just bars and a bed where they can see me 24 hours a day cause they thought I might kill myself which doesn't make sense because Im going to die anyway.

Over time this woman has learned more about HIV and has realised that immediate death is not the reality of an HIV diagnosis.

I thought you get sick once and you die. But no. You get sick, you get better and you can get sick again and get better and there are so many diseases you can get.

Expectations of longevity range from immediate death to a few years. One man thought he would die within six months.

I thought back then that if you got HIV it was immediate, you know, six months (and) you're gone. And then I started reading about people living like eight, ten, twelve or more years and that's what really changed. I thought that if you got the HIV infection that you were going to be gone very shortly.

I kept thinking it was going to be immediate. I thought it was diagnosis and then death. I didn't realise there was life after diagnosis.

Another man describes coming to the realisation that death is not going to come soon.

I think you really think that you're going to be gone just like that, you know. (But) you're not, you say,'I'm here, I'm still alive, you know". 
These experiences may be described as 'beating the odds', one of the actions within the core experience of Surviving the HIV Diagnosis.

The action of 'changing expectations' is used by people as they try to balance what they think will happen with what is actually occurring in their lives.

I had moments when I first discovered it that, you know, I thought "Well, I'll just cash everything in and I'm going to go and take a big vacation" and then I thought "Well, what if I blow all my money then my worst fear is going to be realised, being impoverished".

Some describe developing an attitude after diagnosis where personal health and preventive care is ignored because there doesn't seem to be any point if you are going to die.

I think every HIV person goes through it and some don't get out of it, that this is the end. Why bother getting teeth fixed because you're going to be dead. Why bother doing this because you're going to be dead. Well, I got over that stage.

One man was devastated by the diagnosis; he had no idea that his test would be positive. He describes the interaction with his physician on learning the news.

I though this is the end of my life, right. I'm going to be gone in months. But then he (the physician) was really comforting because he said, "Don't worry about it. Even though you are positive it's not the end of the world. People live for years and years with this virus".

Although somewhat comforted this man still thought he did not have much time left. "This is the last year Im going to see."

However, after some months had passed, he realised that he had 
indeed survived longer than he had originally thought possible. It was then that he began to see what may lie ahead; that he could outlive the prediction of longevity that he had set for himself. This attitude defines the action of 'surviving in good health'.

Like after six months I accepted it, that I was HIV. But then after about six months I started to realise, yea, this is it, may as well make the best of what you've got.

One man describes how he was told to expect about two years before he would die. Eight years later he remains healthy.

I was told that probably I could look at about two years, Fooled them...I've grown somewhat complacent with my longevity.

Some were told what to expect from their physicians. That this was "an eventual death sentence."

My doctor was very thorough in explaining what was going to happen and everything else, that your T4s were going to go down and eventually it was, you were, I was going to wind up with full blown AIDS and it was just a matter of time one way or another though it was pretty definite that I was going to die you know.

When the expected does not happen, when the person seems to be Surving the HIV Diagnosis, a variety of reactions occur. Within these reactions is the action of 'beginning to hope'.

Five years ago or five and a half years ago I was tested positive and I didn't think I would ever get to this point and sit back and go, "Well Im still here and Im still healthy which is great". 
One person changed physicians after being diagnosed and went to a specialty HIV clinic.

The clinic gave me hope, told me what to do. What things that I can do to strengthen myself and increase my life expectancy and well, I'm still her aren't I?

This man attributes his survival to taking care of himself and to a positive attitude. Others see no personal responsibility for longevity but rather that this is due to luck.

I seem to be lucky. HIV wise anyhow, you know. I haven't gotten any (opportunistic infections). I must have a mild strain. It's taken a long time.

For those that have known about their HIV infection for a number of years that feeling of fear and certain death is a distant memory.

There's many stages in life and also stages in HIV. So you get to a certain point that you sometimes forget about the past. How you first felt. And when new people come into the support group with a lot of anger, a lot of hysteria about it, it's a reminder. To remind yourself that that's how you used to be and that maybe you can help, give them some support for the to get out of that stage.

These ten individuals have all exceeded what they thought would be the length of their life after being diagnosed. For some that length of time was an arbitrary number of months or years, formed from a general opinion and a lack of knowledge about the natural history of HIV infection. Some were told what to expect by health care professionals based on medical knowledge from the early days of treating HIV and 
ADS. Through the actions of beating the odds, changing expectations, surviving in good health, and beginning to hope, they have survived the HIV diagnosis.

\section{Taking Care}

The pursuit of health while living with HIV encompasses spiritual, psychological, and physical dimensions. The action of 'embracing spiritual beliefs' is illustrated by those for whom religious faith is important and has become a source of great comfort and strength.

I pray a lot. Yea, my religious beliefs are deep held but I can, in prayer I can talk to God, like if I haven't talked to anyone else all day, I can talk to him. Like he's my best friend. And do all that sharing and thanksgiving and praise and ask for help and guidance as well. And that's a source of comfort for me.

None of the individuals interviewed attend church services but many had a sense of a higher power.

I've expanded my spirituality in the aspect of how one has to commit with whatever God that they believe there is. One has to connect with that and God could be yourself and you have to reconnect to yourself.

One man attributed his sense of well being to his feelings of spirituality.

I would like to think it's my sense of spirituality or my inner growth. It could be luck really, but I just like to think it.

Without HIV I would still have been a victim. I was a victim all my life. HIV has meant learning about my life... I plan to walk with the gods, not ahead of them, not behind them, but with the gods, and that's basically what it's taught me. It's getting beyond fear. 
'Monitoring stress' is another action used in taking care. The role that stress plays in life is important to these individuals. Some believe that stress will lower their T4 count and will ask for a T4 count to be done whenever they feel that they have experienced stressful events.For example, if I go through a stressful period then I always want to get my T4s checked because I know that that has, I believe that the two things that most profoundly affect my health are stress management and attitude and so if Tve had a particularly difficult go around then IIl boogie in there (doctor's office) to get T4s checked.

For some people, the level of their T4 count is very important and they wait for the results nervously.

I wish they'd take a T4 count every month, you know, but they only do it about every second or third or fourth month.

When I first got tested and I got my first T4 count and it was very low, it was like 270 , and I realised now that it was the stress of all that because in the next few years the mean jumped up to around 400 and now it's at 300 or less again.

Sometimes the daily experiences of living are stressful in themselves. Those who are employed must try to lessen the effects of stress in the workplace.

I think I probably could have taken on a lot more work than I really have. Like we've got a really good reputation in this business and I think that I could have taken on a lot more than we presently have but I don't because like along with a lot more work comes a lot more stress. 
The stress of working and what was going on at work and what was going on with my health, and people at work wondering are you positive or do you have AIDS and are you gay and all of that running around at work didn't help any. So the stress was a major problem and I think I've taken a lot of the stress out of my life.

For those who are deliberately trying to live life differently because they are HIV infected, there may be stress inherent in making the changes purported to improve the quality of life.

'Cause there are so many stressors going on for me...you know, these lessons of giving yourself permission and doing it just for yourself. They all sound great but they are very hard for me to institute.

Controlling stress may involve meditation, listening to music, relaxation tapes, or simply taking time out to go for a walk.

I go for a walk and I think and I talk to myself.

I've got my music room and I listen to it (music) in my care as well. I put it on a good station...I tend to more tranquil music at home and then I tend to listen to upbeat music while I'm driving. I love music.

My self meditation is listening to quiet or tranquil music...I call it loving music in that it has loving thoughts. It could be contemporary music, classical, tribal. I call it healing music because it tends to heal the inner spirit wither by music or by the words or the message.

I do a lot of self-meditation and inner searching and it tends to ground me too. Some people would think that it's a waste of time but I find that it is more helpful because you actually don't waste time. You recollect your thoughts and look at your goals and redefine yourself again. And sometimes you get off course but self-meditation helps you redefine where you want to go. 
I use relaxation tapes a lot, not a lot but if I feel really

stressed out from work or whatever, I use a relaxation tape for when I go to bed. Just lay down and relax.

For many of these individuals, getting the news about being HIV positive forced then to make lifestyle changes and this is the third action used in the core experience Taking Care.

It put a whole new responsibility on me to deal with the virus in a productive way and keep myself well.

I feel like I'm treating myself as well as I know how to treat myself...if someone feels or tells me that maybe I've been doing something wrong and I could be treating myself better, I will listen to them and say that I will try it.

It's not always been but even more so now, in my mind, that I take good care of my body as far as eating, getting good rest, not overdoing or anything. Trying to eliminate as much as possible any stress that I have in my life.

Some of the participants seem to have gained a sense of what the body is telling them and they are more responsive to signals from within.

I watch more as to what I put into my body and what's going on with my body and I pay more attention to what I do than what I don't do. Really make sure that I take care of myself so for me it's got to a point where it's almost the best thing that's happened to me.

Like you start to think about your body and it's health and I've always been sort of in tune with what's happening inside and if there's something wrong I can sense it or feel it. 
Taking care of oneself may precipitate other changes too. One man has managed to lower his blood pressure by changing his diet.

Tve managed through my lifestyle changes and what not to get off the blood pressure medications which is a real treat after eight or nine years of that.

I've packed up drinking, packed up smoking, changed my diet considerably...a gradual process of improving my lifestyle to achieve longevity.

One of the common ways people take care of themselves is through diet.

I've changed my diet. I eat...I'm starting to eat a lot better now than what I used to.

I've been following that Canada Food Guide where I've been eating all my portions that I'm supposed to and what more can I do ? Like I'm eating healthy. I don't drink. I don't smoke. And at most times I feel healthy.

I used to eat irregularly. Now it's on a more regular basis that I eat.

I was thinking of going to one of those support groups cause you want to know what other people are doing to stay healthy, like what they are eating, what kinds of things.'Cause you hear so much about all these herbs and that that will help.

I'm much less cavalier about my health and my control and what I can do now. I made a big effort this summer to eat right and exercise.

Many people take vitamin and mineral supplements. For those on a fixed income, this may not be possible as they tend to be fairly expensive and are not covered by Social Assistance. 
Like if they help, they help. I mean, I can afford to buy them. Why not take them ?

And I really believe and I believe this because I keep running into a common denominator with this, with the people that I talked to who are into vitamins in some way or another. And I believe that, you know, certain things are good for people that are HIV positive.

I'm not sitting and popping tons of pills every day. I have certain ones that I take like garlic and I take a lot of vitamin C, a lot more than I ever used to, and zinc and folic acid, some of the things that I've heard are low in HIV positive people.

It's very routine. It's in the morning. I put them in my front shirt pocket and when I get to work...Another thing that I'm doing a lot of, I'm eating a lot of carrots. I actually enjoy them now so I eat my carrots and then I'll take my pills during the day.

Most people recognise the detrimental effects of alcohol, nicotine, and other substances and attempt to cut down or eliminate these substances from their lives.

I've pretty well changed my drinking of alcohol and beer and that probably is the reason my T4 count is quite high.

I just want to say one thing about the impact of alcohol and your immune system. I found in my own little uncontrolled test, that my tobacco cessation had a much more profound effect on $\mathrm{T} 4 \mathrm{~s}$ than my alcohol cessation.

Im fighting this sober and clean, like not doing no drugs and Tm sober.

I think also the drinking cessation has had a major impact on how I feel and not only from the physical standpoint. 
'Seeking medical advice' is one of the ways of taking care. Most of the individuals interviewed had relatively high T4 counts and were not on any medication. They tend to see a physician two or three times a year to get routine blood tests performed and between visits, they know that they can contact their health care professional by telephone should they have a concern.

I only go when there's a problem. The only time I see the doctor is, I think it's twice a year, just to get my T4 cells done and just regular blood work and stuff like that unless something comes up.

Because I'm so healthy I get my tests done every six months, just to see how I'm doing and chat with the doctor.

The nature of the relationship between client and physician is important. Knowing that the physician has experience working with HIV infection promotes confidence.

When I got fed up with my (first) doctor's lack of knowledge on the subject and decided to go to the clinic where I had been told I should have gone in the first place but I had been reticent to go through the pre- and post-test counselling, because I figured I knew what I was talking about... I might as well be where they know the most and that was the point at which I really turned around.

Some feel that they ask for medical intervention when they have tried to deal with the problem by themselves and need help. This promotes the idea of a partnership between the individual and health care professionals. 
I go and see the doctor when I need to, not because six months is up. I also feel that I'm in touch enough with what's going on in my body that if Ive got a problem that I don't understand or can't relate to any specific thing, that I go and get it sorted out.

Not everybody likes doctors... but when something comes up, I phone my doctor and my doctor will say, "Come right in, we'll have a look at you" or "Go to the hospital emergency right away, I'll let them know you're on your way and we'll take it from there".

'Cause of I do have any problems or whatever, I'll tell them and my doctor asks me all the time like if I'm depressed a lot or if I ever think about suicide or... I don't want to kill myself, I want to live.

Taking care also involves avoiding others with colds and flu. This action can be described as 'avoiding other infections'. Although all the participants recognised that they would not get seriously ill if they did catch a cold, most of them were cautious about being in contact with people who were sneezing and coughing.

I avoided people for a while and very quickly learned, as soon as that cold and flu season started, that if I was going to live like this I was going to have to live in a bubble.

If I know that somebody's got a cold or flu or whatever, I kind of keep my distance.

If I know that somebody's got something that might affect me, I just take my precautions, you know. If they cough I'l turn my head the other way without even, sometimes without even thinking about it. I just sort of go like that cause they didn't turn their head.

If somebody's really sniffling up a storm, then I watch things like Kleenex they throw around and wash my hands and wash my face and wash my moustache and that kind of stuff. 
The last action in Taking Care is that of 'accessing information'. Finding out about HIV is another way of taking care. The search for knowledge can start at any time and takes place in many different ways. It may begin soon after diagnosis as the person attempts to cope with having HIV. Formal strategies for gaining information include talking to health care providers and subscribing to treatment bulletins. Informal sources of information include talking to other HIV infected individuals and gathering information from the media.

I was going through that period of trying to cope and trying to deal with myself being positive, the need for information and more involvement on my part was getting greater.

When I was first diagnosed we got pamphlets and that. The only thing now I really look for is information on new drugs that they are making or testing and if anything else is working.

Information is available from many different sources and people use what they can and in whatever format best suits them.

I read it in the newspapers or see it on TV. That's enough.

I subscribe to some treatment bulletins from the States, Toronto, and Vancouver and try to keep up with what's happening in the bigger communities.

I borrow library books. I grill my HIV nurse, call about a lot of things.

I get information from my doctor and Fll go to the library and see what they have and general information for the news which half the time I don't go with because the way the media blows things out of proportion. I'd rather turn around and get it from a researcher and my own personal doctor than from the news. 
Just reading different articles and whatnot in the paper or attending seminars...we attended a seminar on alternative medicines and this sort of thing. Anything that comes up like this I will attend to check to see if there's maybe something to it.

Most acknowledge that there is a great deal of information and it is difficult to absorb it all. There are also some times when people seem more in need of information than others. Keeping up with the vast amount of information available may also pose problems for people with limited time or energy.

I could probably be more knowledgeable but where do you stop ? The quest could be continual and the information is changing daily and you could make it a life quest to try and keep up with it. I deal with it at the time when something happens and $\Gamma \mathrm{m}$ not going to go on a life's crusade of following everything that's being developed or researched.

There are so many drug studies and this test and that and printed articles that most of it I just let slip by. But now and again there is something that I read that clicks and makes sense that helps me understand things.

At one point I really didn't want to be bothered with what was going on with all of these therapies because I really didn't want to think about what was going on and what may happen and what may not happen so I tried to stay away from it. But then I decided at one point that I'm responsible for my personal health care and if I don't know what's happening....

For those who attend a support group, that forum becomes a place to share information. This is particularly useful for those who do not have access to the library or who may be unable to understand 
articles in journals or even the newspaper.

In our group it's quite informative and we find out the latest issues and some people are quite into that so I do hear about it which is quite interesting.

And now I go through the stuff when it comes in and if there's something about an OI (opportunistic infection) that a friend of mine is having trouble with then I try and pass the information along.

However, gaining information can have negative effects particularly when therapies once touted as promising are reported as not being useful after all. People with HIV place great importance on new advances and findings because there have been so few successful treatments in the past.

If I read an article about something, a new test they're doing or whatever, and they fail and that really gets me down. So I try not to read anything about it.

Taking care is an important part of living with HIV. It contains many of the actions people use in daily activity including embracing spiritual beliefs, monitoring stress, making lifestyle changes, seeking medical advice, avoiding other infections, and accessing information. Living in the Present

All the individuals interviewed described a heightened sense of the importance of every day. This may be felt in a positive sense for some or in a negative sense when thinking there is no future.Living in the present involves the actions of 'changing goals', 'making every moment 
count', and 'viewing the future'. Living in the present profoundly alters the way people respond to events in their lives.

Life before HIV for many of these individuals meant planning a career and setting long term goals. This has now changed. For some the change is profound.

Well, at times there is no future. I can't see the future. It's just the present, what's going on now.

There's really no past or future.

I really don't plan far ahead. I just take it on a daily basis. Everything's changing all the time and sometimes that's even hard to keep up with.

In the past I'd be thinking, "Well, two years from now maybe I'm going to take a trip to Europe" or something like that and of course now I can't think of things like that.

I think I take my professional life a little, look at it a little differently now. To me there is no more further developments for a career and at my age I actually should have a career already.

Some, particularly those who have seen only minor changes in their T4 count, are able to look ahead but plans tend to be made in the short rather than in the long term.

I can't really set any long term goals. I hopefully will be around in the next 10 or 15 years. I might not but I'm just setting short term goals. One of the plans is by June we're planning on getting into a house. I haven't set any major goals that I want to get through. 
The second action in this core experience, 'making every moment count', stems from an intensity in living in the here and now. Some recognise that there will be a tomorrow while for others the experiences of this moment in time are enough.

I feel like I want to make sure that today is good and want to do a little preparation to avoid major disasters tomorrow and that's about all I worry about.

I don't procrastinate about things, I sort of look for now.

I'm more conscious of time. It's just I don't want to waste it. I've gotten to the point where there's no point in me worrying about things that have happened in the past because I can't change the past and it's my responsibility to take care of what's going to happen to me in the future.

If I'm having a really good time I don't want it to end.

One man found that he could not maintain the intensity of living purely in the present and making each and every moment count.

And although it's unfortunate that you've got less time, you just do the best with what you can but you can't overdo it and you can't stuff too much stuff in there. T've tried it. It doesn't work. You can't maintain that intensity. Practically it doesn't work.

Living in the present is not necessarily easy. Many of those interviewed saw it as yet another part of working to live within the confines of the illness.

I just make the best of each day, each day as it goes by. I don't normally plan ahead or anything. I just take each day as it comes. 
Day to day. Day to day. You never think about what's going to happen at the end of the year or anything like that. Once it comes, it comes.

I'm going to do what I can today and enjoy my life while I can and I'm going to live it to the fullest and what I can't do then I can't do it. I'm just going to have to accept that.

I'm more conscious of what I do right now and on a day-today basis I do things that I would normally not do like take care of myself, sit down and spend three or four hours reading a book as opposed to saying, "Oh well, Tve got lots and lots of time, Ill do this next week". I figure well, I feel like doing it now, $\Gamma \mathrm{m}$ going to do it now because you never know, next week I might be deathly ill and dead in two weeks. So I do live more in the day and take care of myself and do what I want to do for me as opposed to doing what other people want me to do for them.

Living with HIV does not take away all goals. It is still possible to look to the future but there is an emphasis on keeping goals and dreams well anchored to the present and to what is possible now. This is the third and final action in this theme, the action of 'viewing the future'.

Maybe I'll plan for six months down the road but that's it. Nothing further.

I'm trying to live, believe it or not, a healthy normal life day to day. And I try to make small goals, not long goals, short ones.

Tve shortened long term goals in terms of more current holidays. Like you know, right now I'm thinking of a car trip to the States so I dwell on that.

I altered the long term goals. You know, like I don't sit and think about at $55 \mathrm{Im}$ going to have a million dollars and $\mathrm{Tm}$ going to retire. 
I'm trying to cram more into now when I know I'm capable and healthy of doing something. Like making a European trip and planning another one again for next year and this sort of thing. You're making the best of the time and opportunity as it happens and comes now.

The ability to look beyond the immediate is affected by physical and mental well-being. If one feels weak or tired it may be difficult to think beyond what is happening now.

Sometimes my motivation and drive just isn't there and I won't do whatever it is I'm supposed to do. So that's why I just do it on a daily basis.

Living in the present affects the relationships these individuals have. There are both positive and negative aspects to this. While their partners may find the intensity and spontaneity exciting at times, there are also times when a reluctance to plan for the future may be frustrating for spouses and partners.

There is some talk that my girlfriend may move in. We're undecided about this, whether the relationship is going to continue or not. Although it's causing me quite of lot of consternation, I'm just enjoying now, the quiet day and not worrying about if it's going to work or if it's not going to work. I'm by myself now. I'm enjoying this private relationship rather than concentrating on what might be.

One man expresses very powerfully the benefits, as he sees them, of living in the here and now. This clearly illustrates the expanding spirituality that has grown from his experiences of living with HIV. He has embraced the fragile nature of life itself and has developed a philosophy for his life today. 
I look at things that are important now, things that I should do now. I believe that it's important to tell people you love them and not wait until you're dead and buried in some ceremony. It's important to do things now. It's important to tell people you care for them and you love them or show them or do the best you can now. Heaven is here and now for me. People tend to wait for heaven before they can be nice. Heaven's the here and now and if when I die, there is nothing else, at least the last bit of consciousness that I will have in my head is that I knew I left love behind for the other generations that will grow up and that's all that's important in the end.

Living in the present affects all dimensions of the human experience. It involves changing goals, making every moment count, and also viewing the future. It takes work but there are benefits to be derived although these may be tempered by thoughts of what might have been.

\section{Seeking Support}

All the individuals interviewed spoke of the importance of other people in their lives and the support they derive from these relationships. Some people share their feelings with only one other person; others rely on a circle of friends who are committed and trustworthy. Family relationships are a vital source of support for some. The presence of trained volunteers also provides support as do health care professionals. Attendance at regular meetings of a support group provides many of these individuals with contact with people who understand what the experience of living with HIV is like on an intensely personal level.

Seeking support makes use of the actions of controlling 
information, telling family and friends, asking for help, drawing closer to others, and attending a support group.

The individuals interviewed all felt a need to control who they told of the diagnosis and when they were told. This may be one way of asserting some control in a situation where the individual had very little real control over what has happened. Some chose to tell only a select number of people in the family; others have not told elderly parents who may well die before there are any visible signs of ill health in the infected individual.

I told my closest sister about it right in the beginning. And that's when we discussed how much further this should go.

I got a few phone calls from family members and their basic problem was not that I was HIV positive but that I didn't tell them any sooner. It was just "Why didn't you tell us, you've done this all this time by yourself and alone and we could have been there for you".

The support of family is very important. The action here is that of 'telling family and friends'. Many told their families and, after an initial period of adjustment, have continued their interactions as before.

My mom phoned and she cried and I cried and she said, "It doesn't change the way I feel about you, you're my son, I still love you". She is very up-to-date on the HIV and ADS issue. I sent her a book when I found out. My whole family has read it and are still very accepting of me. They say, "Well, you're the same person as you were yesterday so what would be the difference?". And my mom is always asking me, "How are you feeling? How are you doing ? Am I eating right? Am I exercising ?" Typical mother questions. We're much closer now than what we were. 
I don't know how they handled it amongst themselves, it's their own business, but they became supportive almost immediately. Got themselves educated and like parents do, they phone me with every quick cure... they called me when they discovered AZT in the newspaper and $I$ had been taking it for like a year.

They (parents) love me and so they were able to overcome their fears to the point of not worrying about it as much.

Friends play an important role in the lives of these individuals.

Some people have maintained the friendships that they have made over the years but have included new friends, generally other HIV positive people, into their circle. These friendships are strong and committed and the openness in these relationships is freeing for the infected person.

There's a lot of friends that I've made as a result of my HIV connections and those friends are particularly good. There's no more secrets and that's a very nice place to be.

The circle of friends that I have, a lot of them are HIV positive and it's something that I really enjoy being around these people but I don't want it to be all of what's in my life. I get together mainly with people that I really enjoy. They know me so well that they know I wouldn't want to constantly talk about it (HIV).

I've always been fortunate enough to have a group of friends that were very supportive and I was able to... it wasn't a secret that I kept for very long. I shared it pretty quickly with my friends.

The social relationships I maintain now are a very few, very strong committed relationships whereas before I might have had many aquaintances. A lot of people would get together but it was always very superficial. 
The act of reaching out and talking about what one is going through is the beginning of support. Communication is the first step and although disclosure of HIV status may be frightening, to many this is the beginning of a lifetime of sharing and love.

One good thing I know that I have and one thing I don't ever want to let go of ever, is the basic open communication between people. I'm finding that if you can talk about it you're starting to heal within yourself.

When you tell somebody something that's devastating like being gay or HIV positive, even if they don't understand it, if they come around it shows how truly much they love you.

I have to talk out to another person and also hear my ideas to see if they are correct because there's no use keeping your ideas in your head... Until you hear it in talking with somebody else, with some feedback, you don't progress.

Trained professionals and volunteers are an important form of support particularly for people who live far from home or don't have many friends they can depend on.. Volunteers are generally used when people have problems maintaining physical independence but sometimes they are a listening ear in the night when everyone else is asleep or a non-judgemental sounding board when family is far away.

My doctor would phone me here at home, make sure I was okay. That makes me feel good 'cause it tells me that my doctor cares. You know, they're not stone cold and the doctor and I do talk together.

They (the volunteers) take me to and from shopping and paying bills. But there's always an opportunity to sit down and have coffee with them at a restaurant, talk about something... and I know it's more of a friendship thing than doing a volunteer obligation because you get involved in their lives too and quickly their concerns become yours. 
When individuals have disclosed to the important people in their lives the response has been positive and often the relationships have been enriched. This can be described as the action of 'drawing closer to others'. There are descriptions of great understanding and a closeness that did not exist before.

It just seemed to bring us closer. A lot closer together. I remember when I first went to the doctor that day and he told me and I thought "Well, $\mathrm{Tm}$ going to be alone now for the rest of my life, he's (partner) going to take off and he doesn't want anything to do with me". But he's very supportive.

A lot of support comes from my partner. He's pretty understanding about what's going on in my life and when I'm feeling good he's quite happy, but when I'm not he's worried about it but he doesn't make an issue of it.

The final action in Seeking Support is 'attending a support group'. Many of these participants attend a support group regularly. The sharing and mutual support is vitally important particularly because all the members of the group have gone through many of the same stages in the course of living with this disease. One man describes the members of the group as his family.

The support group are some of the six to sixteen best friends I have ever had. It's not like I would have gotten to know any of these people any other way. With the exception of my own blood brother, I consider them all my family. All my own brothers.

In our group we very seldom talk about our T4 count which is good. We know the people who are ill and that's important. 
Talking to them on a regular basis and helping them through their problems helps me a lot. And it opens my eyes and just reminds me that this could be me and I could be having these problems and $\mathrm{Tm}$ really happy to be helping other people get through their problems.

It is clear that in seeking support, many find themselves in a supporting role which is often of great benefit. Seeking support involves controlling information, telling family and friends, asking for help, drawing closer to others, and attending a support group. Supportive relationships may build on existing friendships or they may begin when mutual needs are recognised.

\section{Appreciating the Positive}

The individuals interviewed describe being diagnosed with HIV infection as a "wake up call" and the impetus to make significant changes in their lives. They talk about appreciating the positive aspects of their lives much more than ever before. The actions in this are 'enjoying life without regrets', 'changing personal attitudes', gaining greater understanding', enjoying relationships', 'contributing to society', and 'dealing with death'. These people seem to express a greater appreciation of what they have now and for the lives they have led in the past.

Enjoying life without regrets can be exciting. One is able to fully appreciate and make the most of every experience .

It makes me think that you should be prepared for all of a sudden a quick demise and it's back to the thing of , you can't take things for granted. 
I feel Tve lived a very rich and fulfilled life, and Im not old at 47 but $\Gamma m$ not young either and if I was to go tomorrow, I don't think Id feel slighted of life if something should happen.

It has made me feel more lucky to be around and Tve always had good health and I take a look at people who haven't had good health and you feel sorry for them and you feel better.

Appreciating the positive involves changing personal attitudes

and looking at things from a different viewpoint. This can be lifeaffirming.

Having a life-threatening illness...it's just why waste your time about stupid things? A lot of people spend years and years and years worrying about a problem that you can't really fix... just look at things differently now.

Tve changed my attitude about a lot of things...I just look at living differently now. I appreciate my weekends, I appreciate my time off and I appreciate my gardening. I appreciate all the things that I like to do a lot more now.

In the last two and a half to three years Tve been thinking a lot differently about things in life and at first it really bothered me knowing (about the HIV) and then I thought,"Well, I can't do anything about it so I might as well deal with what's going to happen or if something happens.

Having HIV has led many of the participants to gain a greater understanding of themselves and who they are in relation to the world.

I used to worry about ridicule or about getting a bad response from a person. Thankfully that's never happened. Im at a point now that if they did react badly it doesn't matter to me. Like it would be their problem. 
I'm starting to believe in myself a lot more now and I push myself a little bit more, pretty well each day. I guess basically to test my own limitations and if I can get a little further each time then I know I'm better in myself in some way.

Goals change. What becomes important changes. My child has become more sacred because of this. Relationships in general.

Some of the positive experiences many of these individuals have had are in the changing nature of their relationships with others. They describe being more open to what others are experiencing and learning more about themselves through seeing what happens to others.

It's given me an opportunity to learn about people and make decisions that I wouldn't have before.

Relationships with people that are more than superficial. To really sympathise as well as empathise with people. Learn what true friendship is.

I feel that $\mathrm{Tm}$ a lot more understanding of people now and I'm not as sharply critical of others.

As a person, I'm more open to what other people are saying and what they're doing and I try to be more concerned with the people around me, how they react to me and how I react to them.

One individual recounted how relationships with a family member had become more meaningful and more affectionate. These individuals were talking and touching for the first time in many years, if not for the first time ever. 
I'm not used to my mom coming and she helps me...she did my dishes. She's been coming around a lot and she hugs me and gives me kisses. And she's not jumping up to hurry up. She makes a pot of coffee and we sit and we drink it and talk. And before...she was, to stop us from talking we'd play bingo or cards.

A few of those interviewed have reached a point where they feel they want to contribute in some way to society and this has been a very enjoyable experience. Some choose to be active in the political arena, by lobbying the government for AIDS funding; others go on speaking engagements and help in the education of the general public and high school students in particular; one or two are involved in volunteer activities such as serving on the board of directors of ADS service organisations.

I think Im a better person for it. And I think Im making a difference because I am that. Prior to this happening I was basically...I didn't talk to anybody and I wasn't open about what I was feeling and what I was doing with my life and now I make a point of, if somebody asks me something, Im more than willing to talk about it.

I really really enjoyed being able to, not so much to enlighten people but to give them the opportunity, not so much experience what I've gone through, but listen to the way I think about things and they're allowed to ask me and they feel more comfortable asking me questions because they've never had to deal with it before.

'Dealing with death' is the final action in appreciating the positive. Thoughts of death are brought to the fore when a HIV diagnosis is made and many of the individuals in this study met the challenge of confronting their mortality early on in the disease process. These 
individuals seem relieved that they have dealt with their mortality and have moved on to meet the challenge of living with HIV. Dealing with death has been a positive experience and has increased their appreciation of life. For some, it has deepened their spiritual beliefs.

I feel I had to deal with the death thing or it was going to be nagging me forever and so I did what I thought I had to do to get myself ready for that and so now I don't worry about that any more. When the creator is ready, I'm ready.

People tend to either fear death or they put it out of their heads like it's never going to happen. Well, HIV brings that to the forefront and says death does happen to everyone... you have to deal with that and come to terms with death... and say that this thing is going to happen eventually so how am I going to make this a peaceful transition.

I've seen too many people go in anger to their deaths with unresolved issues, fearing death, with a turmoil of family problems around them which doesn't help the dying person. I plan to do it a peacefully as I can and if my family can't be peaceful when I die, I don't want them there.

One man plans to leave a legacy to his young child. He writes an entry in a journal almost every day and plans to leave this journal for his child.

There's a sense of, you become really mortal with this. Otherwise you just assume your kids will find out about you, you'll be there and all of a sudden this disease is telling you that you may not be there. And I'd like her to know me and if she can't know me by being with me then perhaps through the pages.

HIV infection has been the impetus for introspection and a resulting growth and strength that goes beyond the normal maturation 
process. These individuals have had to think about life and death at a time when other people their age are concentrating on careers and mortgages.

I did a lot of inward searching what my beliefs are and what I really believe about myself.

It's made me change my philosophy. It's made me change my self-identity and really, most of my concepts have changed.

I think it's seen me grow. I think I've reached a level of maturity that I never would have reached without having to deal with a crisis like this.

I've become stronger I think. Like mentally I think I've become stronger because I can put up with a lot more now.

You have to reconnect with yourself and find your centre of yourself, your being, and be in peace with yourself. HIV has made me come to grips with that, that I have to find that peace whatever it may be.

Appreciating the positive means rediscovering what is important for the individual and is achieved through six actions. These encompass the gifts of enjoying life, altering attitudes, learning about oneself and others, relationships, making a contribution to society, and facing death.

\section{Trustworthiness}

The findings of the thematic analysis have been validated according to three principles, namely fittingness, auditability, and credibility. This enhances the trustworthiness of the results.

Two of the ten respondents did not fit exactly into the theory of the development of a new perspective on life. These two individuals 
described loneliness and a sense of shame associated with their diagnosis of HIV infection. Their experience of HIV has not been a positive one, however they had begun to see their life in a different way and perhaps with time they will begin to formulate positive perspectives from their experience. They spoke about being robbed of a future and feeling little hope however they did acknowledge that since diagnosis they were seeing their life differently.

Auditability was confirmed by having a member of the thesis committee review the transcripts, memos, and notes of the ten interviews. One suggestion made after this process was to review the transcripts of the two individuals who seemed to not fit with the rest. Observations stemming from this review will be detailed in Chapter Six.

Creditability for the findings of this research have been confirmed through auditability, reviewing the journal kept by the researcher, and the reporting of the findings to participants in the study.

Reflection and Reflexivity

The research process was an opportunity for me to re-establish contact with individuals whom I had cared for in my practice as HIV Nurse Clinician in a community health clinic. Although I had known these individuals for up to five years, their stories had a profound impact on me.

In the interviews I deliberately steered the conversation away from the role I had played, as HIV Nurse Clinician, in the care and education of these ten individuals. This role was in some cases quite 
significant in that I had been the one to tell someone that he or she had tested positive for antibodies to the virus. Over the past six years I have come to know all of these individuals well and had at least monthly contact with most of them. Some of the participants mentioned my role in their journey in the interviews. I chose to ignore this in the analysis and deliberately did not include any quotes which referred to me or any mention of 'the nurse'.

I was struck by the strength and courage desplayed by these people in living with a disease that despite all early predictions, continues to baffle scientists. I was humbled by the dignity with which they face life within the limitations forced on them by reduced income and health. I was welcomed into their homes and made to feel comfortable. All my questions and probes were answered with honesty and generosity.

In the years that I have worked with those infected with HIV, I have seen so many die. There have been times in the past where I have found myself despairing of my ability to bring comfort and make a difference. It seemed as if despite my best efforts, all my clients would inevitably die. While my purpose was not to prevent the inevitable, I still found it difficult to maintain hope in what at times seemed like a hopeless enterprise.

Through the research process I have once again witnessed the majesty of the human spirit which has no boundaries and no limitations. People are faced with immense hurdles and they overcome time and 
time again, and move on to face ever greater challenges.

One experience within the analysis of the data took me somewhat by surprise. I had coded the transcripts and was ready to begin writing the thematic portion of the thesis. The coded transcripts were in a binder in chronological order and I found myself struggling to pick out useful quotes for the analysis. The binder was full and the pages did not move easily as I looked through the transcripts. After half a day of frustration, I came to the realisation that I need to cut up the transcripts and group quotes in different categories and themes. However, I found this very difficult to do; I could not 'cut up' the lives of these people, I could not 'cut up' the people themselves. After a day and a half of agonising over this, I did manage to achieve this and the analysis was much easier thereafter.

This research has in many ways been a continuation of the learning and understanding begun when I first became interested some years ago in the experiences of people with HIV and AIDS . Interacting and listening to the life stories of those who live with terminal illness has made me appreciate the positives in my life; good health and the ability to think clearly, the prescence of loved ones and the joy they bring to the mundane and special events in life, the vision of a future which is unfettered by the limitations of disease and disability.

\section{Conclusion}

This chapter has described the findings of the study. Quantitative data was analysed. The thematic analysis has identified the 
phenomenon of Gaining a New Perspective of Life through living with uncertainty. Five core expereinces support this. They are Surving the HIV Diagnosis, Taking Care, Living in the Present, Seeking Support, and Appreciating the Positive. Each core experience is comprised of actions which the infected individual undertakes while living with the uncertainty of HIV infection.

Finally, the researcher has looked inward to examine the personal effects of the research experience and the impact that it has had on personal growth. 
CHAPTER SIX

\section{DISCUSSION}

Introduction

This chapter will present a discussion of methodological issues and compare the findings of this study with other theories and research in the field. Particular attention will be paid to how the findings relate to Mishel's reconceptualisation of the Uncertainty in Illness theory. As well, suggestions for further study will be made. The usefulness of these findings will be discussed in relation to the education of health care professionals involved in caring for people with HIV infection. Suggestions for counselling those living with HIV will also be made.

\section{Methodological Issues}

The small size of the sample restricts the generalizability of the results of the quantitatve survey. However, the interviews provided rich contextual data from which the thematic analysis was derived.

The results of this study may also be restricted in that all the participants receive medical care from physicans in the community as opposed to in hospital out-patient clinics and this may be a form of selection bias. All the participants in the interviews had had prolonged contact with the researcher over the past five years. The nature and quality of these interactions may have biased the results. As well, the number of women who participated in the survey is small and only one woman was interviewed. 
Respondents were asked to participate in in-depth interviews based on their score on the Mishel Uncertainty in Mllness Scale. Ten individuals were asked to participate in interviews irrespective of whether the reseacrcher had an opinion as to the potential quality of their responses in an interview. Richer data might have been gathered if ten people were interviewed who were felt to be potentially valuable informants irrespective of whether they scored high or low on the MUISC.

Two of the ten individuals interviewed described their experience as being shameful and isolating. There was no evidence of this shame in the eight other interviews. Further sampling may fill in the theory to capture the stigma or shame, or the experience of these two individuals may be seen to be a reflection of their unique experience and different from the majority of people with HIV infection.

The transcripts of the ten individuals who participated in the interviews were reviewed and compared to their score on the MUIS-C. There does not appear to be any relation between high or low score on the MUIS-C and the development of a new perspective on life. Of the two people who had experienced shame and stigma as a result of being diagnosed with HIV infection, one had scored high and one low on the MUIS-C. This may reflect a weakness in the ability of the scale to capture the nuances of uncertainty or may be a result of the small sample size of this study. It is also possible that scoring low for a measure of uncertainty reflects the feeling of despair in living with a life- 
threatening illness. The individual may have little uncertainty about the illness and the certainty he or she feels about the illness and the future may lead to feeleings of hopelessness and depression rather than the development of a new perspective on life.

The interviews were conducted using a list of questions and prompts. Participants were encouraged to add any comments they wished and the questions were all open-ended. At no time were participants asked directly about their experience of uncertainty, the questions dealt with issues that would be affected by uncertainty, such as changing goals and issues related to social support and information seeking. The data compiled in the interviews may have been different if direct questions about uncertainty had been used.

The decision was made to not ask direct questions about uncertainty in illness to avoid any emotional distress to the participants. The participants may not regard themselves as being uncertain and any probing of this could cause them to question their coping behaviour. None of the ten individuals who participated in the interviews asked about their scores on the MUIS-C. They expressed interest in the outcome of the study as a whole but not in their individual results or scores.

While some studies have described the experiences of those living with HIV/AIDS as self-transcendence, this issue was not addressed directly in the interviews. It was felt that this is a complex concept to understand and might easily have been confusing for participants. 


\section{Theoretical Issues}

Mishel (1990) has stated that individuals who experience uncertainty related to illness over a period of time may experience a dismantling of existing cognitive structures that give meaning to life. It is theorised that this disequilibrium state favors the development of a new perspective on life that is more complex than the one previously held. Two criteria exist within this theory, that of an essential time period over which the uncertainty exists (temporality) and a threshold of uncertainty in the illness experience.

Probabilistic thinking is the corner stone of this new perspective. Probabilistic thinking involves the ability to focus on multiple alternatives and choices and a consideration of the fragility of life itself and the many different situations one may find oneself in. It is based on the assumption that nothing is certain in life and that anything may happen (Mishel, 1990).

Fundamental to this reformulation is the impact of social resources and health care providers on the individual. The theory states that the new perspective on life is fragile and the individual must continually strive to maintain this orientation. Social resources and health care providers are vital for the maintenance of this orientation. They must support the probabilistic thinking seen as the cornerstone of this new perspective on life.

This study has shown that a new perspective on life is possible for those living with HIV infection. The criterion of temporality has been 
met in that all the individuals have been living with HIV infection for a period exceeding two years and in some cases, as long as eight or nine years. Many of these individuals may have been infected with HIV long before they were tested for the virus. Some suspected they were infected for months or years before testing but chose not to test for personal reasons. For others, no effective test existed before 1984 and thus they lived with their suspicions until they were able to test. Still others had no conscious thought of being HIV infected and were shocked to discover this when they did test positive for antibodies to the virus.

Another criterion is that of a threshold of uncertainty within the illness experience. HIV infection in its essence meets the requirements of great uncertainty. There is no cure for this disease and few effective treatments. Disease progression is unpredictable and contains vague symptoms and often rare manifestations of opportunistic infections.

This uncertainty is theorised to form the basis of probabilistic thinking as the uncertainty is accepted as the natural rhythm of life. Participants in this study described not making long term goals and accepting what life presented each new day. There was evidence of personal flexibility when short term plans did not work out. Life was being experienced in the here and now and people were seen to be open to change.

Within the use of probabilistic thinking is the ability to focus on multiple alternatives and possibilites. Participants used this mechanism to alter goals and enjoy new possibilites. For example, making plans to 
go on short weekend holidays while still healthy instead of delaying. One man was using a daily journal to leave a legacy for his child who might not have the opportunity to get to know him in the future when the child will be older.

Additionally, probabilistic thinking involves reevaluation of what is important in life and this is evidenced in this study by those who realised the importance of relationships over money and have modified their work habits accordingly. Another marker of probabilistic thinking is the ability to reconsider personal investments and many of the respondents spoke eloquently of the importance of love and close bonds within the family. One man in particular described how his business relationships have changed and how he has become a better person and employer in the business world. Finally, recognition of the fragility of life is essential to probabilistic thinking and the many descriptions of making every moment count testify to the attainment of that perspective in many of these participants.

Support from family and friends is seen as essential to the development and maintenance of the new perspective on life. Acknowledgement of the state of uncertainty is vital to building trust and also to protecting the importance of loving relationships within the confines of a world where no one person has all the answers. The importance of supportive and loving relationships is born out in this research study. The core experience Seeking Support details the many and varied actions used by HIV infected individuals as they control 
information, tell family and friends, ask for help, and draw closer to important people in their lives. The circle of support is even wider in some cases where help is given to others in a support group situation at the same time as help is received.

Mishel (1990) describes four barriers to the development of a new perspective on life. The first relates to the individual's support system not promoting a probabilistic view of life. The second barrier pertains to individuals who are primary caregivers and who delay their response to illness because of care giver responsibilites. The third barrier is that of social isolation and the fourth is health care providers who continue to search for certainty within the illness experience of the patient or client.

In this study, no evidence was found to support any of these situations strongly. Most of the participants have indeed shown evidence of forming a new perspective on life. Even for those who have restricted social contacts, strong social support within those confines does exist and is supportive of the new perspective on life. The isolation expereinced by some of the particiapnts is often of their own choosing and may be a reflection of personal style rather than a response by others. All the individuals interviewed receive medical care at a facility which is strongly supportive of multiple alternatives to problems and problem solving.

Another theory that deals with uncertainty and the structuring of a new reality is Selder's Life Transition theory (1989). This theory is based on the concept of relinquishing an old pre-illness reality and 
restructuring a new reality. The success of the development of this new reality is dependent on the ability to relinquish the old at the same time as recognising losses and the permanency of the new state.

Some of the strategies utilised in the formation of a new reality are information seeking, comparative testing by relating to others in similar circumstances, and living in the present.

The findings of this research support Sender's theory in part. People were seen to seek out information and to use support group meetings as an opportunity to compare themselves to others. As well, a core experience of the thematic analysis was that of Living in the Present.

A major difference between Sender's theory and Mishel's reconceptualisation of the Uncertainty in Illness theory is that Sender contends that individuals seek to reduce uncertainty in a variety of ways while Mishel suggests that the continued presence of uncertainty is essential to the formation and maintenance of a new perspective on life which encompasses probabilistic thinking.

There is no evidence from this research to support Sender's contention that uncertainty is reduced in an attempt to restructure reality. While the participants did strive to seek out information, they seemed to incorporate the uncertainty of living with HIV into their lives.

This study thus lends support to Mishel's reconceptualisation of the Uncertainty in Illness theory. While limited in sample size and selection of a study population of individuals who are experiencing one 
aspect of the disease continuum, some credibility is given to this new theory. This support for Mishel's reconceptualisation of the Uncertainty in Illness theory is tentative. Mishel's language is not specific and more practical information and empirical evidence from other research is needed to provide additional support.

The core experiences of Taking Care, Seeking Support, and Appreciating the Positive described in this research are similar to the self-care activities described by Allan (1990). Allan's study found that consultation with other HIV infected individuals about health maintenance activities such as life-style changes reduced uncertainty. Attitudinal adjustments also reduced uncertainty by focusing on the positive and remaining optimistic.

Benner Carson (1993) found that hardiness in people with HIV/AIDS was associated with prayer, exercise, and meditation While this research did not examine hardiness, some of the participants engaged in prayer and meditation. It is interesting to note that exercise was not mentioned by any of the participants as an activity routinely used to reduce stress or increase well-being. This may be due to weather conditions in an area where it is cold for eight months of the year and in a sample that were mostly unemployed and thus could not afford membership fees to a club or gym.

While this research did not investigate the experience of selftranscendence, some elements of this may be drawn from the core experiences of Taking Care, Living in the Present, Seeking Support, and 
Appreciating the Positive. The participants described activities that are encompassed by the three criteria of Frankl (1969) as selftranscendence. They contribute creatively to the world through family and work; they receive from the world by asking for and accepting help from friends, family and others, and they have accepted living with the challenge of a life-threatening illness.

Coward and Marcus Lewis (1993) have found very similar themes to the ones in this research in their study of eight gay men with AIDS. The themes of experiencing several sources of fear and having hope are similar to the core experience of Surviving the HIV Diagnosis. The themes taking care of oneself and accepting help are described in this research under the core experience of Taking Care. The core experience of Seeking Support encompasses the themes of connecting with others and accepting help. The core experience of Appreciating the Positive is similar to Coward and Marcus Lewis' theme of letting go, accepting what cannot be changed and creating a legacy.

The study of self-transcendence in gay men by Coward and Marcus Lewis (1993) involved only men with an AIDS diagnosis which may have influenced the depth and range of the experiences described. However, the similarities with this study which explored the consequences of uncertainty in living with HIV infection lends support to the credibility of both studies.

\section{Implications for Research}

It would be helpful to repeat this study in a population whose 
disease has progressed to a case diagnosis of AIDS. Those who are facing death in the more immediate future may have additional insights and experiences to share. Many may have lived for a longer period of time with greater uncertainty or may have experienced a different perspective on life for both a longer time and in the face of different challenges.

In addition, the experiences of men and women with HIV/AIDS may be different in terms of the consequences of sustained uncertainty. The interview sample comprised nine men and one woman. Of the ten individuals interviewed, eight identified themselves as homosexual, one as bi-sexual, and one as heterosexual. There may be experiences that are unique to the life circumstances of these individuals based on their social status and past experiences. The small size of the sample in this study and the unequal distribution of numbers between the three groups (homosexual, bi-sexual and heterosexual) preclude any conclusions being drawn related to these factors.

Implications for HIV Infected Individuals

This research has highlighted certain behaviours that seem significant. Most of the individuals have made adjustments to improve their life style. Some take vitamins, others have given up drinking, some have altered their diets. These changes are likely an attempt at personal involvement in therapeutic efforts when medical interventions are not indicated. Personal actions such as these are likely empowering and people seem to feel better for making them. 
Most of the indviduals stated that they have sought out information. However, this is not always a positive experience. Some found that learning more about HIV was frightening and chose to not continue with this. Others are strengthened by the knowledge gained and share this information with others.

The importance of family support is striking in the results of this study. While the initial reaction of family may be negative, the end result is usually that of unconditional love and support. This is information that people with HIV, particularly those who have recently been diagnosed, should know. While there appears to be no benefit to waiting until one is sick before telling family and friends, the decision to do so remains with the infected individual. This delay may be a strategy to exert control in a situation where very little control exists. The initial response of family and friends may be the same but in the interim, years may have passed when the infected individual could have been the recipient of great support.

It is interesting that in this study sample, no one was receiving private counselling. The participants reported dealing with any problems they may have alone, with a significant person in their life, or in a support group. This may reflect the paucity of trained counsellors in the city who are involved in the counselling of homosexual men and in the field of HIV/AIDS. It may also point to the lack of counselling services offered to those of low income or on Social Assistance who cannot afford private counselling which is not covered under the health care system. 
Lastly, the importance of a support group to many of the individuals who participated in this study cannot be ignored. In this forum, people share past and present experiences. They support each other emotionally and with information about the disease and treatment options. For some, the members of the group are family. Implications for Nursing Education and Practice This research suggests that there is benefit to be derived from accepting the presence of uncertainty in the illness experience. Gaining a new perspective on life is viewed by those affected as a positive experience. Nurses, and indeed other health care professionals, should be taught that the search for certainty and prediction may not always be necessary. In medicine, aggregate data about a disease are used to yield an average life expectancy for those with the disease. These are usually based on physical findings and do not take into acccount other factors which may influence disease progression (Hall, 1990). Thus predictions about life expectancy and disease course are generally not reliable.

While patients and their families may initially ask for prognoses and predictions of life expectancy and disease progression, it may in fact be more useful to work with these individuals to foster a probabilistic view. This may allow those infected and affected by illness to consider multiple and different alternatives to dealing with problems and to alter patterns of behaviour in an attempt to adjust to new circumstances.

Probabilistic thinking is not linear and much of the education in the past has focused on linear models of disease and interventions. 
However, many nursing interventions, particularly those used with chronically ill individuals and their families, are based on non-linear principles and emphasize multiple alternatives and adaptations to altered states of functioning.

People living with chronic or life-threatening illness should be encouraged to seek information from a variety of sources including members of the health care team, their family and friends, and others in a similar situation. No one person will necessarily have the one correct response or suggestion. Probabilistic thinking has at its core the concept of multiple alternatives. The support of peers which may be found in attendence at a support group may provide such alternatives. Many of the individuals attending a support group may have attempted alternative ways of dealing with symptoms and feelings experienced while living with a disease and may make suggestions for the resolution of problems or avoidance of complications.

This view and practice should be encouraged, not only with chronically ill patients, but also for those with acute disease. A probabilistic viewpoint allows for greater creativity and growth and fosters an openness and flexibility in both the nurse and the patientfamily unit.

This research has shown how important the love and support of family is to those who have disclosed to their families. While many individuals are reluctant to cause their families emotional upset, it may be appropriate to encourage them to disclose as the benefits of the love 
and support are important and most families are able to overcome the initial shock and sadness and are then able to support each other.

The prescence of hope in the terminally ill is not evidence of denial. Treating it as such may take away hope from the terminally ill individual and impedes the development of a trusting relationship between health care provider and patient (Hall, 1990). Fostering hope where appropriate is an important aspect of probabilistic thinking. The patient, and not the health care provider, must however dictate the context and parameters of that hope.

\section{Conclusion}

The purpose of this study was to explore the consequences of uncertainty in the lives of people with HIV infection. The extent of uncertainty was measured by asking individuals with HIV infection to complete the Mishel Uncertainty in Illness Scale. The results of this survey showed that these individuals do experience a range of uncertainty with the majority of the individuals participating falling close to the range of the mean found in other disease populations. The experience of this uncertainty was described eloquently and forms the basis of the narrative section included in this thesis. The consequences of living with this uncertainty have been analysed and a phenomenon, Gaining a New Perspective on Life, was discovered. This is supported by five core experiences which detail the experience of living with uncertainty within the context of HIV infection. 


\section{References}

Allan, J.D. (1990). Focus on living not dying : a naturalsitic study of selfcare among seropositive gay men. Holistic Nursing Practice, $\underline{4}(2)$, 56-63.

Bailey,J.M., \& Nielsen,B.I. (1993). Uncertainty and appraisal of uncertainty in women with rheumatoid arthritis. Orthopaedic Nursing, $12(2), 63-67$.

Bartlett,J.G., \& Finkbeiner,A.K. (1991). The Guide to Living with HIV Infection. Baltimore,MD : The Johns Hopkins University Press.

Benner Carson,V. (1993). Prayer, meditation, exercise and special diets : behaviours of the hardy person with HIV/AIDS. Journal of the Association of Nurses in AIDS Care, $\underline{4}(3), 18-33$.

Bennett,S.J. (1993). Relationships among selected antecedent variables and coping effectiveness in post myocardial infarction patients. Research in Nursing and Health, 16, 131-139.

Berer, M. (1993). Women and HIV/AIDS : An International resource Book. London : Pandora Press.

Brown,M.A. \& Powell -Cope,G.M. (1991). AIDS family care giving : transitions through uncertainty. Nursing Research, 40 (6), 338345 .

Burnard, P. (1991). A method of analysing interview transcripts in qualitative research. Nurse Education Today, 11, 461 - 466. Christman,N.J., McConnell,E.A., Pfeiffer,C., Webster,K.K., Schmitt,M., \& Ries,J. (1988). Uncertainty, coping and distress following MI : 
transition from hospital to home. Research in Nursing and Health, $\underline{11}, 71-82$.

Cohen,F.L. (1991). The etiology and epidemiology of HIV infection and AIDS. In J.D.Durham \& F.L.Cohen (Eds.), The Person with AIDS: Nursing Perspectives. New York :Springer Publishing Co.

Cohen,M.H. (1993). The unknown and the unknowable - managing sustained uncertainty. Western Journal of Nursing Research, 15(1), 77-96.

Coward, D.D., \& Marcus Lewis, F. (1993). The lived experience of selftranscendence in gay men with AIDS. Oncology Nursing Forum, 20(9), 1363-1368.

Frankl,V. (1969). The Will to Meaning. New York : New American Library.

Gaskins, S., \& Brown,K. (1992). Psychosocial responses among individuals with HIV infection. Applied Nursing Research, $\underline{5}(3)$, 111-121.

Gee,G. (1988). Individual psychosocial responses to HIV infection. In G.Gee and T.A.Moran (eds.), AIDS : Concepts in Nursing Practice. Baltimore, MD: Williams and Wilkins.

Guba,E.G., \& Lincoln, Y.S. (1981). Effective Evaluation. San Fransisco : Jossey Bass.

Hall, B.A. (1990). The struggle of the diagnosed terminally ill person to maintain hope. Nursing Science Quarterly, $\underline{3}, 177-184$. 
Health Canada (1994). Quarterly Surveillance Update : ADS in

Canada. Ottawa : Health Promotion Branch.

Hilton, B.A. (1992). Perceptions of uncertainty : its relevance to lifethreatening and chronic illness. Critical Care Nursing, 12(2), 7073.

Kendall,J. (1994). Wellness spirituality in homosexual men with HIV infection. Journal of the Association of Nurses in AIDS Care, $\underline{5}(4)$, 28-34.

Kostbade Hughes,K. (1993). Psychosocial an functional status of breast cancer patients. Cancer Nursing, 16(3), 222-229.

Lamendola,F.P. (1994). The paradox of HIV/AIDS as expanding consciousness. Advances in Nursing Science, 16 (3), 13-21.

Laryea, M., \& Gien,L. (1993). The impact of HIV positive diagnosis on the individual : part I. Clinical Nursing Research, Aug., 245-266.

Manitoba Health (1994). HIV/AIDS Statistical Report. Winnipeg,Mb. : Community and Mental Health Services Division.

Mishel,M.H. (1984). Perceived uncertainty and stress in illness. Research in Nursing and Health, $7,163-171$.

Mishel,M.H. (1988). Uncertainty in illness. Image, 20(4), 225-232.

Mishel, M.H. (1990a). Reconceptualization of the uncertainty in illness in illness theory. Image, 22(4), 256 - 262.

Mishel,M.H. (1990b) Uncertainty in Illness Scales Manual. Available from Dr M.Mishel, School of Nursing, CB \# 7460 Carrington Hall, University of North Carolina, Chapel Hill, NC 27599-7460. 
Mishel,M.H., \& Braden,C.J. (1988). Finding meaning : antecedents of uncertainty in illness. Nursing Research, 37(2), 98-103.

Mishel,M.H., Padilla,G., Grant,M., \& Sorenson,D.S. (1991). Uncertainty in illness theory : a replication of the mediating effects of mastery and coping. Nursing Research, $\underline{40}$ (4), 236-240.

Mishel,M.H., \& Sorenson,D.S. (1991). Uncertainty in gynaecological cancer : a test of the mediating functions of mastery and coping. Nursing Research, 40 (3), 167-170.

Poole,L. (1990). HIV infection in women. In P.T.Cohen, M.A.Sande \& P.A.Volberding (Eds.), The AIDS Knowledge Base. Massachusetts : The Medical Publishing Group.

Redeker,N.S. (1992). The relationship between uncertainty and coping after coronary bypass surgery. Western Journal of Nursing Research, 14(1), 48-68.

Reed,P. (1991). Self-transcendence and mental health in oldest-old adults. Nursing Research, $\underline{\text { 40, 5-11. }}$

Ross, M.W., Tebble, W.E.M., \& Viliunas, D. (1989). Staging of psychological reactions to HIV infection in asymptomatic homosexual men. Journal of Psychology and Human Sexuality, 2(1), 93 - 104 .

Sandelowski, M. (1986). The problem of rigor in qualitative research. Advances in Nursing Science, 8 (3), 27-37. 
Sandelowski, M. (1993). Rigor or rigor mortis : the problem of rigor in qualitative research revisited. Advances in Nursing Science, $\underline{16}(2), 1-8$.

Schechter,G.F. (1990). Mycobacterium tuberculosis. In P.T.Cohen, M.A.Sande \& P.A.Volberding (Eds.), The AIDS Knowledge Base. Massachusetts : The Medical Publishing Group. Shilts,R. (1987). And the Band Played On.New York: Penguin Books. Siegel,K., \& Krauss, B.J. (1991). Living with HIV Infection : adaptive tasks of seropositive gay men. Journal of Health and Social Behaviour, $\underline{32}, 17-32$.

Strawn,J.M. (1991). The psychosocial consequences of HIV infection. In J.D.Durham \& F.L.Cohen (Eds.), The Person with ADS : Nursing Perspectives. New York, NY : Springer Publishing Co.

Tross, S., \& Hirsch, D.A. (1988). Psychological distress and neuropsychological complications of HIV infection and AIDS. American Psychologist, 43(11), 929 - 934.

VanDevanter,N.L. (1991). HIV testing and counselling. In J.D.Durham \& F.L.Cohen (Eds.), The Person with AIDS : Nursing Perspectives. New York, NY : Springer Publishing Co.

Volberding,P.A. (1990a). Clinical applications of anti viral therapy: overview. In P.T.Cohen, M.A.Sande \& P.A.Volberding (Eds.), The AIDS Knowledge Base. Massachusetts : The Medical Publishing Group. 
Volberding,P.A. (1990b). Clinical applications of anti viral therapy : use of zidovudine. In P.T.Cohen, M.A.Sande \& P.A.Volberding (Eds.), The AIDS Knowledge Base. Massachusetts : The Medical Publishing Group.

Volberding,P.A., \& Cohen,P.T. (1990). Clinical spectrum of HIV infection. In P.T.Cohen, M.A.Sande \& P.A.Volberding (Eds.), The ADS Knowledge Base. Massachusetts : The Medical Publishing Group.

Webster,K.K. \& Christman,N.J. (1988). Perceived uncertainty an coping post myocardial infarction. Western Journal of Nursing Research, $10(4), 384-400$.

Weitz, R. (1989). Uncertainty and the lives of persons with AIDS. Journal of Health and Social Behaviour, 30, $270-281$.

Wiener,C.L., \& Dodd,M.J. (1993). Coping amid uncertainty : an illness trajectory perspective. Scholarly Inquiry for Nursing Practice, $\underline{7}(1), 17-31$. 


\section{Bibliography}

Merton,R.K., Fiske,M., \& Kendall,P.L. (1956). The Focused Interview : A Manual of Problems and Procedures. Glencoe,Illinois: The Free Press. 
Appendix 1

Definitions 


\section{Uncertainty}

The inability to determine the meaning of illness-related events.

Operationalized as an inability to assign definite value to objects or events and/or an inability to predict outcomes accurately.

\section{Inference}

General beliefs about oneself and one's relationship with the environment.

Operationalized as learned resourcefulness, sense of mastery and locus of control.

\section{Illusion}

Beliefs constructed out of uncertainty which are viewed in a particular light that emphasises their positive aspects.

Operationalized as wishful thinking and positive thinking.

\section{Coping}

Attempts made by the individual to reduce the stress associated with a particular situation.

Operationalized as mobilising (direct action, information seeking) and affect-management (faith, disengagement).

\section{Adaptation}

Biopsychosocial behaviour occurring within a person's individually defined range of usual behaviours.

Operationalized as psychosocial adjustment, recovery, stress, life quality, or health.

Source : Mishel, M.H. (1988). Uncertainty in Illness. Image, 20(4). 


\section{Appendix 2}

Recruitment Call 


\section{Recruitment Call}

Hello.....................(name)

This is Anne Katz calling. You may remember me from Village Clinic where I worked for the last four years.

You may remember a conversation we had early in the Fall of this year when I told you I was returning to university to complete a Masters degree in Nursing. Part of the program is the completion of a research study and naturally I have chosen to study more about HIV infection.

I will be studying the experiences of people living with HIV and I was wondering if you would be interested in participating in my study. You would be required to fill out a questionnaire which would take about twenty minutes. Your name will not appear anywhere on the questionnaire. I may ask you to participate in a longer interview at a later date. My study has been approved by the Ethical Review Committee of the Faculty of Nursing.

You may of course refuse and this will not influence the care you receive in any way. If you need some time to think about this, I will leave my telephone number with you and you can contact me if you are interested. I hope to begin the study in December 1994.

Thank you for listening to me... do you have any questions? 
Appendix 3

Letter of Support 
November 16,1994

To whom it may concern:

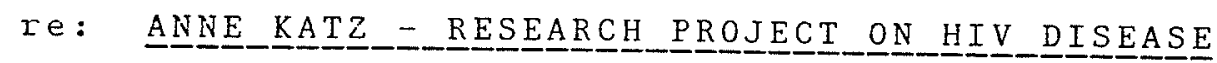

I have reviewed the study prospectus and have spoken with Anne Katz re: her research project on "Uncertainty in the lives of people with HIV disease".

I am satisfied with the legitimacy and value of this study and would/will recommend my clinical patients for participation should they be willing and qualify under the inclusion criteria.

Sincerely,

Craig Skoglund, BSC, MD

CAS * $1 \mathrm{~b}$ 


\section{Appendix 4}

\section{Poster}


A NURSE FROM THE UNIVERSITY OF MANITOBA IS CONDUCTING RESEARCH INTO THE EXPERIENCES OF PEOPLE LIVING WITH HIV INFECTION

IF YOU ARE HIV + (BUT DO NOT HAVE AIDS)

\section{ASK DR SKOGLUND FOR MORE INFORMATION}


161

Appendix 5

Information Sheet 
Consequences of Uncertainty in the Lives of People with HIV Infection

My name is Anne Katz and I am a nurse who is currently a student in the Masters of Nursing program at the University of Manitoba.

I am beginning a research study needed to finish my degree. Dr Smith has agreed to assist me in finding people willing to participate in the study. However, he will not know which of his patients will be interviewed and any personal information about you has not been released to me.

I have worked in the field of HIV/ADS for a number of years and am interested in finding out more about how people with HIV infection deal with uncertainty about the disease, treatment, and the future.

I will be asking people with HIV infection to fill out a questionnaire. This will take about twenty minutes and can be done in your home, at my house, or at some other location. I will ask some participants if they are willing to take part in a longer interview at a later date. This interview will take between one and two hours to complete. All information I obtain will be kept confidential.

If you are interested in helping me with this study, please contact me at If I am not available to answer your call, please leave a message and I will call you as soon as possible. I hope to begin this study in December 1994.

Thank you for taking the time to consider this request.

Anne Katz RN BN 
Appendix 6

Consent Forms 


\section{Consequences of Uncertainty in the Lives of People with HIV Infection}

In signing this consent form, I am giving my consent to be interviewed by Anne Katz, a registered nurse who is conducting a study as part of the requirements for a Master of Nursing degree from the University of Manitoba, Faculty of Nursing. I understand that I will be part of a study focusing on the experiences of people living with $\mathrm{HIV}$ infection.

I understand that I will be interviewed in my home or some other mutually agreed to location. I will be asked to complete a questionnaire and $I$ understand that the researcher may ask me to participate in an interview at a later time.

I agree to participate in this study freely. I have been informed that my participation is entirely voluntary. I can refuse to answer any specific question and I can terminate my participation at any point. I have been told that no reports of this study will ever identify me in any way because no names will be used. My participation or nonparticipation or refusal to answer any questions will have no effect on services that I may receive from health care providers. My physician will have no knowledge of who does or does not take part in the study.

This study is intended to help develop a better understanding of the experiences of people living with HIV infection however I will receive no direct benefit as a result of participation.

All data from the study will be kept under lock and key for a period of seven to ten years. This study has been approved by the Ethics Review Committee of the University of Manitoba, Faculty of Nursing. The advisor for this study is Dr Linda Kristjanson (\# 

HIV Infection

I understand that the results of this research will be given to me if I ask for them and that Anne Katz is the person to contact if I have any questions about the study or about my rights as a study participant. 


\section{Consequences of Uncertainty in the Lives of People with HIV} Infection

In signing this consent form, I

am giving my consent to be interviewed by Anne Katz, a registered nurse who is conducting a study as part of the requirements for a Master of Nursing degree from the University of Manitoba, Faculty of Nursing. I understand that I will be part of a study focusing on the experiences of people living with HIV infection.

I understand that I will be interviewed in my home or some other mutually agreed to location. The interview may take two hours to complete. I agree to participate in this study freely. I can refuse to answer any specific question and I can terminate my participation at any point. If I request it, the tape recorder used in the interview can be switched off. My participation or nonparticipation or refusal to answer any questions will have no effect on services that I may receive from health care providers. My physician will have no knowledge of who does or does not take part in the study.

All data from the study will be kept under lock and key for a period of seven to ten years. This study has been approved by the Ethics Review Committee of the University of Manitoba, Faculty of Nursing. The advisor for this study is Dr Linda Kristjanson (\#

The only people who will see the data from this study are Anne Katz and the members of her thesis committee (Dr L. Kristjanson, Dr. E. Hanson, and Dr. D. Dudgeon) as well as the typist who transcribes the interviews. Any identifying information, such as names, will be removed from the transcripts. At some later time, the results of this study may be published in professional journals but no names will be included and all identifying information will be removed. 
I understand that the results of this research will be given to me if I ask for them and that Anne Katz is the person to contact if I have any questions about the study or about my rights as a study participant.

Date
Researcher's signature

Respondent's signature 


\section{Appendix 7}

Mishel Uncertainty in Illness Scale

Community Form 


\section{MISHEL UNCERTAINTY IN ILLNESS SCALE COMMUNITY FORM}

Please read each statement. Take your time and think about what each statement says. Then place an " $\mathrm{X}$ " under the column that most closely measures how you are feeling TODAY. If you agree with a statement, then you would mark under either "Strongly Agree" or "Agree". If you disagree with a statement, then mark under either "Strongly Disagree" or "Disagree". If you are undecided about how you feel, then mark under "Undecided" for that statement. Please respond to every statement.

The following information is required for demographical reasons only.

Gender : Male [ ] Female [ ]

Year of birth : 19

Years of education :

Thank you for participating. 
1. I don't know what is wrong with me.

Strongly agree Agree Undecided Disagree Strongly Disagree 5

43

2

1

2. I have a lot of questions without answers

Strongly agree Agree Undecided Disagree Strongly Disagree 5

4

3

2

1

3. I am unsure if my illness is getting better or worse

Strongly agree Agree Undecided Disagree Strongly Disagree 5

4

3

2

1

4. It is unclear how bad my symptoms will be Strongly agree Agree Undecided Disagree 5 4 3 2 1

5. The explanations they give me about my condition seem hazy to me

Strongly agree

5

Agree Undecided Disagree Strongly Disagree 4 3 2

6. The purpose of each treatment is clear to me Strongly agree Agree Undecided Disagree Strongly Disagree 5 4 3 2 
7. My symptoms continue to change unpredictably

Strongly agree

5

Agree Undecided Disagree Strongly Disagree 4 3 2 1

8. I understand everything explained to me Strongly agree Agree Undecided Disagree Strongly Disagree 5 4 3 2

9. The doctors say things to me that could have many meanings Strongly agree Agree Undecided Disagree Strongly Disagree 5 4 3 2 1 $-$

10. My treatment is too complex to figure out Strongly agree Agree Undecided Disagree 5 4 3

2 Strongly Disagree $-$

11. It is difficult to know if the medications I am getting are helping

Strongly agree Agree Undecided Disagree Strongly Disagree 5

4

3

2

1

\section{Because of the unpredictability of my illness, I cannot plan for the future \\ Strongly agree Agree Undecided Disagree Strongly Disagree 5 4 3 2


13. The course of my illness keeps changing. I have good and bad days

Strongly agree Agree Undecided Disagree Strongly Disagree 5

4

3

2

1

14. I have been given many different opinions about what is wrong with me

Strongly agree

5

Agree Undecided Disagree Strongly Disagree

4

3

2

1

15. It is not clear what is going to happen to me

Strongly agree Agree Undecided Disagree Strongly Disagree 5 4 3

2

16. The results of my tests are inconsistent

Strongly agree Agree Undecided Disagree Strongly Disagree 5 4 3

2

1

17. The effectiveness of the treatment is undetermined

Strongly agree Agree Undecided Disagree. Strongly Disagree 5 4 3 2 1

18. Because of the treatment, what I can and cannot do keeps changing

Strongly agree

5

Agree Undecided Disagree Strongly Disagree $\begin{array}{llll}4 & 3 & 2 & 1\end{array}$ 
19. I am certain they will not find anything else wrong with me Strongly agree Agree Undecided Disagree Strongly Disagree 5 4 3 2 1

20. The treatment I am receiving has a known probability of success

Strongly agree Agree Undecided Disagree Strongly Disagree 5 4 3 2 1

21. They have not given me a specific diagnosis Strongly agree Agree Undecided Disagree Strongly Disagree 5 4 3 2

22. The seriousness of my illness has been determined Strongly agree Agree Undecided Disagree Strongly Disagree 5 43 2 1

23. The doctors and nurses use everyday language so I can understand what they are saying Strongly agree Agree Undecided Disagree Strongly Disagree 5 4 3 2 1

(C) Merle Mishel, Revised 1990 


\section{Appendix 8}

Interview Guide 
As you know, my study is looking at how people with HIV infection experience uncertainty in their lives. I would like to know how you deal with having this disease and how it affects you in your daily life.

1. Can you tell me how long you have known that you have HIV?

2. Do you think about having HIV often?

3. How do you cope with living with HIV infection?

Probes : changes in daily life ; vigilance of symptoms

4. Has having HIV changed the way you think of yourself?

Probes : Feeling dirty, responsible for disease; personal growth

5. Has having HIV changed your view of the future?

Probes : altered plans; career decisions

6. Has having HIV altered the way you perceive of time?

Probes : does time seem to go faster or slower; living in the present

7. Have your social relationships changed as a result of having HIV?

Probes : disclosure to others; fear of being abandoned; understanding of living with HIV

8. Where do you receive support from?

Probes : support group (informal and formal); friends; health care providers

9. Have your needs for information about the disease changed over time

Probes : sources of information (health care providers, media, newsletters, support group); present level of knowledge vs what person thinks he/she should know

10. Do you worry about catching something from people around you?

Probes : protecting self from colds/flu; understanding how immune system functions

Your experience has been that of........(summarise). Am I correct? Would you like to add anything? Thank you for making the time for this interview and for sharing your experiences with me.

Source : Adapted from M.H.Cohen (1993). 


\section{Appendix 9}

Ethical Review Committee Approval 
The University of Manitoba

FACULTY OF NURSING

ETHICAL REVIEW COMMITTEE

\section{APPROVAL FORM}

\section{Proposal Number_N\$94/30}

Proposal Title: "CONSEQUENCES OF UNCERTAINTY IN THE LIVES OF PEOPLE WITH HIV INFECTION."

Name and Title of

Researcher(s):

ANNE KATZ, RN, BN

MASTER OF NURSING GRADUATE STUDENT

FACULTY OF NURSING

UNIVERSITY OF MANITOBA

Date of Review: NOVEMBER 07, 1994.

APPROVED BY THE COMMITTEE: NOVEMBER 07, 1994.

Comments: $\quad$ APPROVED WITH SUBMITTED CLARIFICATIONS RECEIVED NOVEMBER 25, 1994.

Date: Lor 291904

Wanda Chernomas, RN, $\mathrm{PhD} \quad$ Acting Chairperson

Lecturer

University of Manitoba Faculty of Nursing

Position

NOTE:

Any significant changes in the proposal should be reported to the Chairperson for the Ethical Review Committee's consideration, in advance of implementation of such changes.

Revised: $92 / 04 / 22 / \mathrm{se}$ 